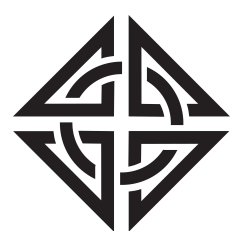

SCIENTIA
Sharif University of Technology

Scientia Iranica

Transactions E: Industrial Engineering

http://scientiairanica.sharif.edu

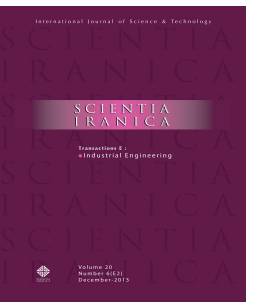

\title{
Linguistic Z-number Muirhead mean operators and their applications in ethical-financial portfolio selection
}

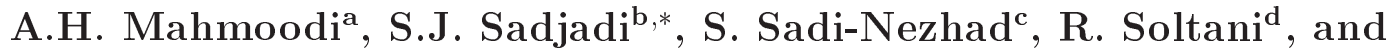 \\ F. Movahedi Sobhani ${ }^{a}$ \\ a. Department of Industrial Engineering, Science and Research Branch, Islamic Azad University, Tehran, Iran. \\ b. Department of Industrial Engineering, Iran University of Science and Technology, Narmak, Tehran, Iran. \\ c. Department of Statistic and Actuarial Science, University of Waterloo, Ontario, Canada. \\ d. Department of Industrial Engineering, Faculty of Engineering, KHATAM University, Tehran, Iran.
}

Received 13 March 2019; received in revised form 13 February 2020; accepted 6 June 2020

\section{KEYWORDS}

Portfolio selection;

Ethical and financial

investment;

$Z$-number;

Reliability;

Aggregation

operators.

\begin{abstract}
Traditionally, the performance of firms is evaluated based on financial criteria; however, the present study aims to propose a new qualitative comprehensive framework that incorporates ethical criteria into the portfolio models and is widely matched with the preferences of socially responsible investors. The increasing trend of corporate deceptions has made investors or fund managers consider the ethical assessments in their investment management. Therefore, it is essential to develop models capable of capturing the ethical and financial criteria in investment processes. In this study, a multi-stage methodology was proposed and linguistic $Z$-numbers were applied to represent the evaluation information. In addition, Muirhead Mean (MM) aggregation operators were employed to fuse the input data into the linguistic $Z$-number environment. To accomplish the objectives of this study, first, four linguistic $Z$-number MM operators were developed. Then, through the max-score rule and score-accuracy trade-off rule, three qualitative portfolio models were proposed. These models were established to maximize the financial performance of portfolio as their main objective, and they were distinguished by the ethical goal the investor follows. The obtained results of numerical example validated the capability of the models in constructing more diversified portfolio based on a trade-off between financial and ethical criteria according to the investors' preferences.

(C) 2022 Sharif University of Technology. All rights reserved.
\end{abstract}

\section{Introduction}

Modern portfolio theory, first introduced by Markowitz [1], emphasizes only financial criteria to

*. Corresponding author. Tel.: +9821 77240129, +9821 73225027

E-mail addresses: amirhosein.mahmoodi@srbiau.ac.ir (A.H. Mahmoodi); sjsadjadi@iust.ac.ir (S.J. Sadjadi);

sadinejad@hotmail.com (S. Sadi-Nezhad);

roya.soltani@gmail.com (R.Soltani); fmovahedi@iau.ac.ir (F. Movahedi Sobhani)

doi: $10.24200 /$ sci.2020.53162.3086 manage assets and selects optimal portfolios. In other words, traditional approaches to asset selection are one-dimensional and they merely concentrate on financial criteria as the basis of evaluation. However, according to existing evidence, the traditional portfolio theory cannot capture all related data only in the form of financial criteria [2]. In addition, there are some growing samples of environmental hazards, corporate deceptions, and social pressures that encourage consideration of social responsibilities in investment processes so as to reinforce the assessment of ethical and financial criteria in investment management. Nowadays, the ethical and social principles such as 
environment, civil rights protection, transparency, and credibility of corporations are regarded as the necessities in the investment processes that should be taken into account.

Therefore, both financial and ethical criteria should be captured simultaneously to construct a more diversified portfolio according to the investors' preferences. An ethical-financial demeanor in investment management called ethical investment or Socially Responsible Investment (SRI) has become widespread around the world since 1960, and the compliance of Environmental, Social, and Governance (ESG) requirements has considerably increased in the last decade. Nowadays, a majority of asset owners, asset managers, and firms publish ESG and sustainability information in their annual reports. According to the latest Global Sustainable Investment Alliance (GSIA) report in 2016, the global sustainable investment assets reached $\$ 22.89$ trillion [3]. The increasing number of SRI bonds is indicative of the growing interest of issuers and investors for sustainable development plans. However, a serious challenge in the ethical investment is the conflict between the ethical and financial objectives that might have negative impacts on the financial objectives such as profitability of investment. In this regard, to better utilize the high potential of SRI markets and carry out a more accurate investigation of the effects of ESG criteria on the portfolio management, some researchers combined the ethical approaches with the investment processes and analyzed their effects on the investors' decisions [4-8]. Therefore, to ensure a trade-off between the ethical and financial criteria in problems of portfolio selection, this study combined the ESG and financial criteria with the asset allocation problem.

Given the inadequacy of their available information, financial markets always encounter uncertainty. Hence, exact quantitative estimation of input parameters is difficult and sometimes impossible. Of note, given that there are some firms that have recently been constituted or newly added to the financial markets, their relative quantitative information is not adequately accessible. These limitations in the performance evaluation of the firms can be omitted through fuzzy set theory [9] and its extended forms, namely the interval-valued fuzzy sets [10], type-2 fuzzy sets [11], intuitionistic fuzzy sets [12], hesitant fuzzy sets [13], and interval-valued hesitant fuzzy sets [14]. The fuzzy set theory and its developed forms are widely used to model portfolio selection problems [15-17]. Despite the significant roles of fuzzy set theory and its extended forms in improving the means of human knowledge representation, they may fail to verify the reliability of information. To overcome this shortcoming, Zadeh [18] introduced the concept of $Z$-numbers. In total, studies whose main focus is on $Z$-numbers can be catego- rized into two groups. The first group is the basic studies that discuss the conversion techniques [19,20], arithmetic operations [21-23], ranking methods [24$28]$, and development researches [29,30]. The second one use $Z$-numbers in the optimization and decisionmaking problems [31-37]. The main advantage of the $Z$-numbers is their ability to model the uncertainty and reliability of relevant information simultaneously. With the increasing complexity of financial markets, this characteristic of $Z$-numbers can help investors and fund managers make more fruitful decisions. Therefore, this study employed the concept of $Z$-number to evaluate the information related to the ethical-financial criteria.

Given the fuzziness, uncertainty, and ambiguity of financial markets, linguistic terms assist Decision Makers (DMs) or experts in real information assessment. For instance, when evaluating the financial and/or ethical performance of a firm, the expert in charge uses linguist terms such as "low", "medium", and "high". These linguistic terms usually include both vagueness and uncertainty. Both fuzziness and randomness are the most significant aspects of uncertainty in linguistic terms [38] that completely match with the possibilistic and probabilistic constraints in $Z$-numbers [39]. In this regard, Peng and Wang [40] introduced uncertain hesitant Linguistic $Z$-Numbers (LZNs). Wang et al. [39] improved the concept of $Z$-numbers and introduced a subclass of $Z$-numbers called linguistic $Z$-numbers that could represent the fuzzy constraint through linguistic terms such as "low", "medium", and "high" and characterize the measure of reliability through linguistic terms such as "seldom", "frequently", and "usually". To be specific, LZN (medium, usually) is applied to evaluate the financial performance of a firm or estimate the future return of an asset. LZNs enjoy several advantages; for instance, they not only reduce information loss by creating a more flexible, holistic, and accurate structure but also capture the possibilistic and probabilistic constraints simultaneously. These properties make the LZNs suitable for evaluating the ethical-financial information in financial markets. In this respect, this study employed the LZNs to evaluate the ethical and financial performances of each firm.

One of the most useful and powerful tools for solving decision-making problems in different uncertain environments is aggregation operator. The main advantage of such operators in comparison with the traditional decision-making techniques is that they can obtain the comprehensive values for alternatives and rank them. Of note, the decision-making techniques modeled based on aggregation operators are preferred over the traditional ones [41]. Over the last decade, aggregation operators have received increased focus for investigation. Some aggregation operators, such as Prioritized Average (PA) operator [42], were developed in positions with exact input arguments. In this regard, 
many scholars have extended aggregation operators in different types of fuzzy environment [43-51]. So far, there are only two aggregation operators in LZN environment called Hesitant Uncertain Linguistic $Z$ numbers Power Weighted Average (HULZPWA) operator and Hesitant Uncertain Linguistic $Z$-numbers Power Weighted Geometric (HULZPWG) operator [40]. All the mentioned aggregation operators are inefficient when it comes to considering the interrelationship between the input arguments and all arguments are assumed to be independent. Hence, some operators such as Bonferroni Mean (BM) [52], Heronian Mean (HM) [41,53], and Geometric Bonferroni Mean (GBM) operators [54] were developed to consider the interrelationship among the input arguments. However, all of these operators have a shortcoming: they fail to capture the interrelationship between all input arguments and consider the interrelationship between only two arguments. Here, the necessity of developing a more holistic operator with the capability of capturing the interrelationship between all input arguments comes to the fore. Muirhead Mean (MM) operator [55] can capture the interrelationship between every input argument. Recently, Liu and Teng [56] proposed some MM operators in a probabilistic linguistic environment. However, no MM operator was proposed in a $Z$ number environment. In this regard, the current study employed the MM operator to fuse the information about LZNs.

As mentioned earlier, the LZNs are more efficient and flexible in information assessment than others, mainly because they can simultaneously capture the possibilistic and probabilistic constraints used for evaluating the information modeling and reduce the information loss due to their more flexible, holistic, and accurate structure. On the other hand, MM operator is able to aggregate the LZN information, and Linguistic Scale Functions (LSFs) are applied to describe different semantic measures. Therefore, the integration of the asset allocation problems with LZNs and MM aggregation operators is very useful. The main motivations behind this study are briefly highlighted in the following:

1. Applying LZNs to evaluate the information related to the ethical and financial performances of firms. This feature makes the proposed approach and models more general and flexible than the traditional portfolio models owing to their ability to capture the reliability of evaluation information in the modeling process;

2. Developing MM operator in a LZN environment and introducing Linguistic $Z$-number Muirhead Mean (LZMM), Linguistic $Z$-number Weighted Muirhead Mean (LZWMM), Linguistic $Z$-number Dual Muirhead Mean (LZDMM), and Linguistic
$Z$-number Dual Weighted Muirhead Mean (LZDWMM) operators;

3. Proposing three qualitative ethical-financial portfolio models based on LZMM, LZWMM, LZDMM, and LZDWMM operators in a LZN environment. The proposed models consider the investors' preferences to construct more diversified portfolios, thus making them suitable for both general and risky socially-responsible investors.

The rest of this paper is organized as follow. Section 2 includes the necessary prerequisite definitions. Section 3 introduces some aggregation operators and their properties in a LZN environment. Section 4 proposes a multi-stage methodology to assign the suitable assets in the portfolio and develops three new qualitative portfolio models in a LZN environment. Section 5 provides the required actual data as the case study and presents the results from sensitivity analysis. Finally, Section 6 concludes this study and suggests further issues to be covered in future studies.

\section{Preliminaries}

\subsection{Linguistic terms set and LSFs}

Suppose that $t_{l} \in T$ is a conceivable value of linguistic variable where $T=\left\{t_{l} \mid l=0,1, \ldots, 2 m\right\} . \quad T$ should contain the following properties $[57,58]$ :

a) $T$ is ordered: $t_{l}<t_{k}$ if and only if $l<k$.

b) $T$ conforms to the negation operator: $n e g\left(t_{l}\right)=$ $t_{2 m-l}$.

$T$ is a discrete linguistic term set. Since the computational results do not usually match the members of $T$. Xu $[59,60]$ introduced a continuous linguistic term set $\bar{T}$ to prevent the loss of obtained information where $\bar{T}=\left\{t_{i} \mid i \in[0, l]\right\}$.

Since computation with linguistic terms is categorized as Computing with Words (CWW), it is quite hard to perform an arithmetic operation; therefore, some functions called LSFs were proposed to simplify the computation in a linguistic environment $[46,60]$. In order to obtain more flexible and efficient information, different semantics were allocated to linguistic terms using LSFs under different circumstances. There is a strictly and monotonically ascending connection between each $t_{1} \in T$ and its label $[46,60]$.

Definition 1. Let $T=\left\{t_{l} \mid l=0,1, \ldots, 2 m\right\}$ be a set of discrete linguistic terms with odd cardinality. The LSF $f$ is defined as [46]:

$$
f: t_{l} \rightarrow \theta_{l} \quad(l=0,1, \ldots, 2 m),
$$

where $\theta_{1}$ is a positive real number and $0 \leq \theta_{0} \leq \theta_{1} \leq$ 
$\ldots \leq \theta_{2 m}$. In addition, $\theta_{l}$ characterizes the priorities of DMs when $t_{1} \in T$ is chosen to express their opinions. Some LSFs are introduced as $[39,46]$ :

$$
\begin{aligned}
\text { LSF1: } & f_{1}\left(t_{l}\right)=\theta_{l}=\frac{l}{2 m} \quad(l=0,1, \ldots, 2 m) \\
& \text { and } \theta_{l} \in[0,1]
\end{aligned}
$$

$\mathrm{LSF} 2: \quad f_{2}\left(t_{l}\right)=\theta_{l}=\left(\frac{l}{2 m}\right)^{m} \quad(l=0,1, \ldots, 2 m)$,

LSF3: $f_{3}\left(t_{l}\right)=\theta_{l}=\left(\frac{l}{2 m}\right)^{\frac{1}{m}} \quad(l=0,1, \ldots, 2 m)$,

LSF4: $f_{4}\left(t_{l}\right)=\theta_{l}$

$$
= \begin{cases}\frac{m^{\alpha}-(m-l)^{\alpha}}{2 m^{\alpha}} & (l=0,1, \ldots, m) \\ \frac{m^{\beta}+(l-m)^{\beta}}{2 m^{\beta}} & (l=m+1, \ldots, 2 m)\end{cases}
$$

where $\alpha$ and $\beta \in(0,1]$.

\section{2. $Z$-numbers and linguistic $Z$-numbers}

This subsection defines the $Z$-numbers, uncertain LZNs, and their operation.

\subsubsection{Z-numbers}

Uncertainty is an inseparable characteristic of real problems. DMs always consider their uncertain data, knowledge, and experiments while looking for the best solutions. In order to make more beneficial decisions, such information must be reliable. Hence, Zadeh [18] introduced the concept of $Z$-numbers to represent the uncertain data better by adding partial reliability and fussiness.

Definition 2 [18] ( $Z$-number). An ordered pair of fuzzy numbers $(\tilde{A}, \tilde{B})$ shows a $Z$-number where $\tilde{A}$, as a fuzzy constraint, represents the values that can be assigned to an uncertain variable $X$, and $\tilde{B}$ determines a soft restriction on a partial reliability of the first component. Both $\tilde{A}$ and $\tilde{B}$ are often expressed through linguistic terms.

\subsubsection{Linguistic $Z$-numbers}

Followed by the study conducted by Zadeh [18], two forms of $Z$-numbers were developed to better describe the uncertain data considering the partial reliability. Peng and Wang [40] introduced the hesitant uncertain LZNs based on the concept of $Z$-numbers and linguistic terms. Wang et al. [39] extended a new form of $Z$ numbers called linguistic $Z$ numbers to measure the reliability of the real phenomena and describe the qualitative data simultaneously.

Definition 3 [39] (Linguistic $Z$-numbers). Consider a universe of discourse $U$. Let two finite discrete linguistic term sets that are indicative of different preference data be defined as $T=\left\{t_{0}, t_{1}, \ldots, t_{2 m}\right\}$ and $T^{\prime}=\left\{t_{0}^{\prime}, t_{1}^{\prime}, \ldots, t_{2 n}^{\prime}\right\}$ where $m$ and $n$ are the nonnegative integers. Therefore, a LZN set in $U$ is defined as follows:

$$
Z=\left\{\left(u, A_{\phi(u)}, B_{\varphi(u)}\right) \mid u \in U\right\},
$$

where $A_{\phi(u)}$ is a fuzzy constraint on the values assigned to the uncertain variable, and characterizes a reliability measure of the first component. $A_{\phi(u)}$ and $B_{\varphi(u)}$ are described using uncertain linguistic terms.

2.2.3. The arithmetic operations over uncertain $L Z N s$ Wang et al. [39] developed some arithmetic operations for LZNs. The proposed operations maintain both the flexibility of linguistic term sets and reliability value of $Z$-numbers.

Definition 4 [39]. Suppose that two LZNs are defined as $z_{i}=\left(A_{\phi(i)}, B_{\varphi(i)}\right)$ and $z_{j}=\left(A_{\phi(j)}, B_{\varphi(j)}\right)$, where $f^{*}$ and $g^{*}$ functions are selected from $f_{1}\left(t_{l}\right), f_{2}\left(t_{l}\right)$, $f_{3}\left(t_{l}\right)$, and $f_{4}\left(t_{l}\right)$. Hence, some operations in a LZN environment are defined as follows:

$$
\begin{gathered}
n e g\left(z_{i}\right)=\left(f^{*-1}\left(f^{*}\left(A_{2 m}\right)-f^{*}\left(A_{\phi(i)}\right)\right)\right. \\
\left.g^{*-1}\left(g^{*}\left(B_{2 n}\right)-g^{*}\left(B_{\varphi(i)}\right)\right)\right) \\
z_{i}+z_{j}=\left(f^{*-1}\left(f^{*}\left(A_{\phi(i)}\right)+f^{*}\left(A_{\phi(j)}\right)\right), g^{*-1}\right. \\
\left(\begin{array}{c}
f^{*}\left(A_{\phi(i)}\right) \times g^{*}\left(B_{\varphi(i)}\right)+f^{*}\left(A_{\phi(j)}\right) \times g^{*}\left(B_{\varphi(j)}\right) \\
f^{*}\left(A_{\phi(i)}\right)+f^{*}\left(A_{\phi(j)}\right)
\end{array}\right), \\
z_{i}=\left(f^{*-1}\left(\rho f^{*}\left(A_{\phi(i)}\right)\right), B_{\varphi(i)}\right) \rho \geq 0 \\
\left.g^{*-1}\left(g^{*}\left(B_{\varphi(i)}\right)^{\rho}\right)\right) \quad \rho \geq 0 . \\
z_{i} \times z_{j}=\left(f^{*-1}\left(f^{*}\left(A_{\phi(i)}\right) f^{*}\left(A_{\phi(j)}\right)\right)\right. \\
z_{i}^{\rho}=\left(f^{*-1}\left(f^{*}\left(A_{\phi(i)}\right)^{\rho}\right),\right. \\
\left.\left.g^{*}\left(B_{\varphi(i)}\right) g^{*}\left(B_{\varphi(j)}\right)\right)\right)
\end{gathered}
$$

Definition 5 [39]. Suppose that $z_{i}=\left(A_{\phi(i)}, B_{\varphi(i)}\right)$ contains LZNs. Then, the score function of the LZN is equal to: 


$$
S\left(z_{i}\right)=f^{*}\left(A_{\phi(i)}\right) \times g^{*}\left(B_{\varphi(i)}\right) .
$$

The accuracy function of the LZN is as follows:

$$
A\left(z_{i}\right)=f^{*}\left(A_{\phi(i)}\right) \times\left(1-g^{*}\left(B_{\varphi(i)}\right)\right) .
$$

Based on the score and accuracy functions, a comparison technique is defined for two LZNs as follows [39]:

I. If $S\left(z_{i}\right)>S\left(z_{j}\right)$, then $z_{i}>z_{j}$;

II. If $S\left(z_{i}\right)=S\left(z_{j}\right)$, then

If $A\left(z_{i}\right)>A\left(z_{j}\right)$, then $z_{i}>z_{j}$;

If $A\left(z_{i}\right)<A\left(z_{j}\right)$, then $z_{i}<z_{j}$.

\subsection{MM operator}

Definition 6 [55]. Let $a_{i}(i=1, \ldots, k)$ be a set of nonnegative real numbers and $P=\left(P_{1}, P_{2}, \ldots, P_{k}\right) \in$ $R^{k}$ a parametric vector. Then, the MM operator is defined as follows:

$$
M M^{p}\left(a_{1}, a_{2}, \ldots, a_{k}\right)=\left(\frac{1}{k !} \sum_{\theta \in S_{k}} \prod_{r=1}^{k} a_{\theta(r)}^{P_{r}}\right)^{\frac{1}{\sum_{r=1}^{k} P_{r}}},
$$

where $(\theta(1), \theta(2), \ldots, \theta(k)) \in S_{k}$ and $S_{k}$ is the set of all permutation of $(1,2, \ldots, k)$.

Definition 7 [61]. Let $a_{i}(i=1, \ldots, k)$ be the set of nonnegative real numbers and $P=\left(P_{1}, P_{2}, \ldots, P_{k}\right) \in$ $R^{k}$ a parametric vector. Then, the Dual Muirhead Mean (DMM) operator is defined as follows:

$$
\begin{aligned}
& D M M^{P}\left(a_{1}, a_{2}, \ldots, a_{k}\right)= \\
& \frac{1}{\sum_{r=1}^{k} P_{r}}\left(\prod_{\theta \in S_{k}} \sum_{r=1}^{k} P_{r} a_{\theta(r)}\right)^{\frac{1}{k !}},
\end{aligned}
$$

where $(\theta(1), \theta(2), \ldots, \theta(k)) \in S_{k}$ and $S_{k}$ is the set of all permutation of $(1,2, \ldots, k)$.

\section{LZMM aggregation operators}

In this section, four types of MM aggregation operators are developed in a LZN environment. The description of MM operators as well as their related properties and theorems are shown in the following.

\section{1. $L Z M M$ operator}

Definition 8. Let $Z=\left\{z_{i}=\left(A_{\phi(i)}, B_{\varphi(i)}\right) \mid i=1\right.$, $\ldots, k\}$ be a set of LZNs and $P=\left(P_{1}, P_{2}, \ldots, P_{k}\right) \in R^{k}$ a parametric vector. Then, the LZMM operator can be defined as follows:

$$
L Z M M^{p}\left(Z_{1}, Z_{2}, \ldots, Z_{k}\right)=\left(\frac{1}{k !} \sum_{\theta \in S_{k}} \prod_{i=1}^{k} Z_{\theta(i)}^{P_{i}}\right)^{\frac{1}{\sum_{i=1}^{k} P_{i}}}
$$

where $(\theta(1), \theta(2), \ldots, \theta(k)) \in S_{k}$ and $S_{k}$ is a set of all permutation of $(1,2, \ldots, k)$.

Theorem 1. Let $z_{i}=\left(A_{\phi(i)}, B_{\varphi(i)}\right)(i=1, \ldots, k)$ be a set of LZNs and $P=\left(P_{1}, P_{2}, \ldots, P_{k}\right) \in R^{k}$ a parametric vector. Then, the aggregated result obtained based on the LZMM operator is an LZN; this is presented by Eq. (16) shown in Box I. The proof of Theorem 1 is given in Appendix A.

Theorem 2 (Commutativity). Let $z_{i}=\left(A_{\phi(i)}, B_{\varphi(i)}\right)$ and $z_{i}^{\prime}=\left(A_{\phi(i)}^{\prime}, B_{\varphi(i)}^{\prime}\right)(i=1, \ldots, k)$ be two sets of LZNs, where $z_{i}^{\prime}=\left(A_{\phi(i)}^{\prime}, B_{\varphi(i)}^{\prime}\right)(i=1, \ldots, k)$ is any permutation of $z_{i}=\left(A_{\phi(i)}, B_{\varphi(i)}\right)(i=1, \ldots, k)$ and $P=\left(P_{1}, P_{2}, \ldots, P_{k}\right) \in R^{k}$ is a parametric vector. Then:

$$
\begin{aligned}
& L Z M M^{p}\left(Z_{1}, Z_{2}, \ldots, Z_{k}\right) \\
& \quad=L Z M M^{p}\left(Z_{1}^{\prime}, Z_{2}^{\prime}, \ldots, Z_{k}^{\prime}\right) .
\end{aligned}
$$

\section{Proof.}

$$
\begin{aligned}
\operatorname{LZ} M M^{p}\left(Z^{\prime}{ }_{1}, Z^{\prime}{ }_{2}, \ldots, Z^{\prime}{ }_{k}\right) & \\
& =\left(\frac{1}{k !} \sum_{\theta \in S_{k}} \prod_{i=1}^{k}\left(Z^{\prime}{ }_{\theta(i)}\right)^{p_{i}}\right)^{\frac{1}{\sum_{i=1}^{k} p_{i}}}
\end{aligned}
$$

$$
\begin{aligned}
& \operatorname{LZM} M^{p}\left(Z_{1}, Z_{2}, \ldots, Z_{k}\right)=\left(f^{*^{-1}}\left(\left(\frac{1}{k !}\left(\sum_{\theta \in S_{k}}\left(\prod_{i=1}^{k}\left(f^{*}\left(A_{\phi(\theta(i))}\right)\right)\right)\right)\right)^{p_{i}}\right)^{\frac{1}{\sum_{i=1}^{k} p_{i}}}\right) \\
& g^{*^{-1}}\left(\left(\frac{\sum_{\theta \in S_{k}}\left(\prod_{i=1}^{k}\left(f^{*}\left(A_{\phi(\theta(i))}\right)\right)^{p_{i}} \times \prod_{i=1}^{k}\left(g^{*}\left(B_{\varphi(\theta(i))}\right)\right)^{p_{i}}\right)}{\sum_{\theta \in S_{k}}\left(\prod_{i=1}^{k}\left(f^{*}\left(A_{\phi(\theta(i))}\right)\right)^{p_{i}}\right)}\right)\right)
\end{aligned}
$$




$$
\begin{aligned}
& =\left(\frac{1}{k !} \sum_{\theta \in S_{k}} \prod_{i=1}^{k}\left(Z_{\theta(i)}\right)^{p_{i}}\right)^{\frac{1}{\sum_{i=1}^{k} p_{i}}} \\
& =L Z M M^{p}\left(Z_{1}, Z_{2}, \ldots, Z_{k}\right) .
\end{aligned}
$$

\subsection{LZWMM operator}

Definition 9. Let $Z=\left\{z_{i}=\left(A_{\phi(i)}, B_{\varphi(i)}\right) \mid i=1\right.$, $\ldots, k\}$ be a set of LZNs and $P=\left(P_{1}, P_{2}, \ldots, P_{k}\right) \in R^{k}$ a parametric vector. In addition, assume that $w_{i} \in$ $[0,1]$ is the weight of the $i$ th input parameter such that $\sum_{i=1}^{k} w_{i}=1$. Then, the LZWMM operator is defined as:

$$
\begin{array}{rl}
L & Z W M M^{p}\left(Z_{1}, Z_{2}, \ldots, Z_{k}\right) \\
= & \left(\frac{1}{k !} \sum_{\theta \in S_{k}} \prod_{i=1}^{k}\left(k w_{\theta(i)} Z_{\theta(i)}\right)^{P_{i}}\right)^{\frac{1}{\sum_{i=1}^{k} P_{i}}},
\end{array}
$$

where $(\theta(1), \theta(2), \ldots, \theta(k)) \in S_{k}$ and $S_{k}$ is a set of all permutation of $(1,2, \ldots, k)$.

Theorem 3. Let $z_{i}=\left(A_{\phi(i)}, B_{\varphi(i)}\right)(i=1, \ldots, k)$ be a set of LZNs and $P=\left(P_{1}, P_{2}, \ldots, P_{k}\right) \in R^{k}$ a parametric vector. Let $w_{i} \in[0,1]$ be the weight of the $i$ th input parameter such that $\sum_{i=1}^{k} w_{i}=1$. Then, the aggregated result based on LZWMM operator is an LZN, which is presented by Eq. (19), as shown in Box II. Similarly, Theorem 3 can easily be proven based on Definition 4 and mathematical induction technique.

Theorem 4 (Commutativity). Let $z_{i}=\left(A_{\phi(i)}, B_{\varphi(i)}\right)$ and $z_{i}^{\prime}=\left(A_{\phi(i)}^{\prime}, B_{\varphi(i)}^{\prime}\right)(i=1, \ldots, k)$ be two sets of LZNs, where $z_{i}^{\prime}=\left(A_{\phi(i)}^{\prime}, B_{\varphi(i)}^{\prime}\right)(i=1, \ldots, k)$ is any permutation of $z_{i}=\left(A_{\phi(i)}, B_{\varphi(i)}\right)(i=1, \ldots, k)$ and $P=\left(P_{1}, P_{2}, \ldots, P_{k}\right) \in R^{k}$ a parametric vector. Then, we have:

$$
\begin{array}{rl}
L Z W & M M^{p}\left(Z_{1}, Z_{2}, \ldots, Z_{k}\right) \\
& =L Z W M M^{p}\left(Z_{1}^{\prime}, Z_{2}^{\prime}, \ldots, Z_{k}^{\prime}\right) .
\end{array}
$$

\subsection{LZDMM operator}

Definition 10. Assume that $Z=\left\{z_{i}=\left(A_{\phi(i)}, B_{\varphi(i)}\right)\right.$ $\mid i=1, \ldots, k\}$ is a set of LZNs, and $P=\left(P_{1}\right.$, $\left.P_{2}, \ldots, P_{k}\right) \in R^{k}$ a parametric vector. Then, the LZDMM operator is defined as follows:

$$
\begin{aligned}
\operatorname{LZD} & M M^{p}\left(Z_{1}, Z_{2}, \ldots, Z_{k}\right) \\
& =\frac{1}{\sum_{i=1}^{k} P_{i}}\left(\prod_{\theta \in S_{k}} \sum_{i=1}^{k}\left(P_{i} Z_{\theta(i)}\right)\right)^{\frac{1}{k !}},
\end{aligned}
$$

where $(\theta(1), \theta(2), \ldots, \theta(k)) \in S_{k}$ and $S_{k}$ is a set of all permutation of $(1,2, \ldots, k)$.

Theorem 5. Let $z_{i}=\left(A_{\phi(i)}, B_{\varphi(i)}\right)(i=1, \ldots, k)$ be a set of LZNs and $P=\left(P_{1}, P_{2}, \ldots, P_{k}\right) \in R^{k}$ a parametric vector. Then, the aggregated result acquired based on LZDMM operator is an LZN, which is presented by Eq. (22) shown in Box III. The proof of Theorem 5 is given in Appendix B.

Theorem 6(Commutativity). Let $z_{i}=\left(A_{\phi(i)}, B_{\varphi(i)}\right)$ and $z_{i}^{\prime}=\left(A_{\phi(i)}^{\prime}, B_{\varphi(i)}^{\prime}\right)(i=1, \ldots, k)$ be two sets of LZNs, where $z_{i}^{\prime}=\left(A_{\phi(i)}^{\prime}, B_{\varphi(i)}^{\prime}\right)(i=1, \ldots, k)$ is any permutation of $z_{i}=\left(A_{\phi(i)}, B_{\varphi(i)}\right)(i=1, \ldots, k)$ and $P=\left(P_{1}, P_{2}, \ldots, P_{k}\right) \in R^{k}$ a parametric vector. Then, we have:

$$
\begin{aligned}
& L Z D M M^{p}\left(Z_{1}, Z_{2}, \ldots, Z_{k}\right) \\
& \quad=L Z D M M^{p}\left(Z_{1}^{\prime}, Z_{2}^{\prime}, \ldots, Z_{k}^{\prime}\right) .
\end{aligned}
$$

\section{4. $L Z D W M M$ operator}

Definition 11. Suppose that $Z=\left\{z_{i}=\left(A_{\phi(i)}, B_{\varphi(i)}\right)\right.$ $\mid i=1, \ldots, k\}$ be a set of $\mathrm{LZNs}$ and $P=$ $\left(P_{1}, P_{2}, \ldots, P_{k}\right) \in R^{k}$ be a parametric vector. Let $w_{i} \in[0,1]$ be the weight of the $i$ th input parameter such that $\sum_{i=1}^{k} w_{i}=1$. Then, the LZDWMM operator can be defined as:

$\operatorname{LZDW} M M^{p}\left(Z_{1}, Z_{2}, \ldots, Z_{k}\right)$

$$
\begin{gathered}
L Z W M M^{p}\left(Z_{1}, Z_{2}, \ldots, Z_{k}\right)=\left(f^{*^{-1}}\left(\left(\frac{1}{k !}\left(\sum_{\theta \in S_{k}}\left(\prod_{i=1}^{k}\left(k w_{\theta(i)} f^{*}\left(A_{\phi(\theta(i))}\right)\right)\right)\right)\right)^{p_{i}}\right)\right)^{\left.\frac{1}{\sum_{i=1}^{k} p_{i}}\right)} \\
g^{*^{-1}}\left(\left(\frac{\sum_{\theta \in S_{k}}\left(\prod_{i=1}^{k}\left(k w_{\theta(i)} f^{*}\left(A_{\phi(\theta(i))}\right)\right)^{p_{i}} \times \prod_{i=1}^{k}\left(g^{*}\left(B_{\varphi(\theta(i))}\right)\right)^{p_{i}}\right)}{\sum_{\theta \in S_{k}}\left(\prod_{i=1}^{k}\left(k w_{\theta(i)} f^{*}\left(A_{\phi(\theta(i))}\right)\right)^{p_{i}}\right)}\right)\right.
\end{gathered}
$$




$$
\begin{aligned}
& \operatorname{LZDM} M^{p}\left(Z_{1}, Z_{2}, \ldots, Z_{k}\right)=\left(f ^ { * ^ { - 1 } } \left(\frac{1}{\sum_{i=1}^{k} p_{i}}\left(\left(\prod_{\theta \in S_{k}}\left(\sum_{i=1}^{k} p_{i} f^{*}\left(A_{\phi(\theta(i))}\right)\right)\right)\right)\right.\right. \\
& g^{*^{-1}}\left(\left(\prod_{\theta \in S_{k}}\left(\frac{\sum_{i=1}^{k}\left(p_{i} f^{*}\left(A_{\phi(\theta(i))}\right) \times g^{*}\left(B_{\varphi(\theta(i))}\right)\right)}{\sum_{i=1}^{k}\left(p_{i} f^{*}\left(A_{\phi(\theta(i))}\right)\right)}\right)\right)\right)
\end{aligned}
$$

Box III

$$
=\frac{1}{\sum_{i=1}^{k} P_{i}}\left(\prod_{\theta \in S_{k}} \sum_{i=1}^{k}\left(P_{i}\left(Z_{\theta(i)}\right)^{k w_{\theta(i)}}\right)\right)_{(24)}^{\frac{1}{k !}}
$$

where $(\theta(1), \theta(2), \ldots, \theta(k)) \in S_{k}$ and $S_{k}$ is a set of all permutation of $(1,2, \ldots, k)$.

Theorem 7. Let $z_{i}=\left(A_{\phi(i)}, B_{\varphi(i)}\right)(i=1, \ldots, k)$ be a set of LZNs, and $P=\left(P_{1}, P_{2}, \ldots, P_{k}\right) \in$ $R^{k}$ a parametric vector. Let $w_{i} \in[0,1]$ be the weight of the $i$ th input parameter such that $\sum_{i=1}^{k} w_{i}=1$. Then, the aggregated result acquired based on LZDWMM operator is an LZN, as presented by Eq. (25) shown in Box IV. Similarly, Theorem 7 can easily be proven using Definition 4 and mathematical induction technique.

Theorem 8 (Commutativity). Let $z_{i}=\left(A_{\phi(i)}, B_{\varphi(i)}\right)$ and $z_{i}^{\prime}=\left(A_{\phi(i)}^{\prime}, B_{\varphi(i)}^{\prime}\right)(i=1, \ldots, k)$ be two sets of LZNs, where $z_{i}^{\prime}=\left(A_{\phi(i)}^{\prime}, B_{\varphi(i)}^{\prime}\right)(i=1, \ldots, k)$ is any permutation of $z_{i}=\left(A_{\phi(i)}, B_{\varphi(i)}\right)(i=1, \ldots, k)$ and $P=\left(P_{1}, P_{2}, \ldots, P_{k}\right) \in R^{k}$ a parametric vector. Then, we have:

$$
\begin{aligned}
& L Z D W M M^{p}\left(Z_{1}, Z_{2}, \ldots, Z_{k}\right) \\
& \quad=L Z D W M M^{p}\left(Z_{1}^{\prime}, Z_{2}^{\prime}, \ldots, Z_{k}^{\prime}\right) .
\end{aligned}
$$

\section{Ethical-financial portfolio selection under LZN environment}

In this section, a qualitative framework is proposed to construct ethical-financial portfolios based on the mentioned aggregation operations in a LZN environment. Experts' experience and opinions are the most important source of data in assessing the ethicalfinancial performance of assets that can be applied to determine the uncertainty and reliability of information simultaneously. The proposed aggregation operators are powerful tools for considering the expert's opinions in a LZN environment. Figure 1 shows the total schematic of the proposed method.

This approach is composed of three stages. In the first stage, the firms are evaluated based on their ethical and financial criteria and then, experts express their opinions about the ethical-financial performance of each firm as a LZN. In the second stage, the ethical

$$
\begin{aligned}
& \operatorname{LZDWM} M^{p}\left(Z_{1}, Z_{2}, \ldots, Z_{k}\right)=\left(f ^ { * ^ { - 1 } } \left(\frac{1}{\sum_{i=1}^{k} p_{i}}\left(\left(\prod_{\theta \in S_{k}}\left(\sum_{i=1}^{k} p_{i}\left(f^{*}\left(A_{\phi(\theta(i))}\right)\right)^{\left.k w_{\theta(i)}\right)}\right)\right)\right)\right.\right. \\
& g^{*^{-1}}\left(\left(\prod_{\theta \in S_{k}}\left(\frac{\sum_{i=1}^{k}\left(p_{i}\left(f^{*}\left(A_{\phi(\theta(i))}\right)\right)^{k w_{\theta(i)}} \times\left(g^{*}\left(B_{\varphi(\theta(i))}\right)\right)^{\left.k w_{\theta(i)}\right)}\right.}{\sum_{i=1}^{k}\left(p_{i}\left(f^{*}\left(A_{\phi(\theta(i))}\right)\right)^{k w_{\theta(i)}}\right)}\right)\right)\right.
\end{aligned}
$$




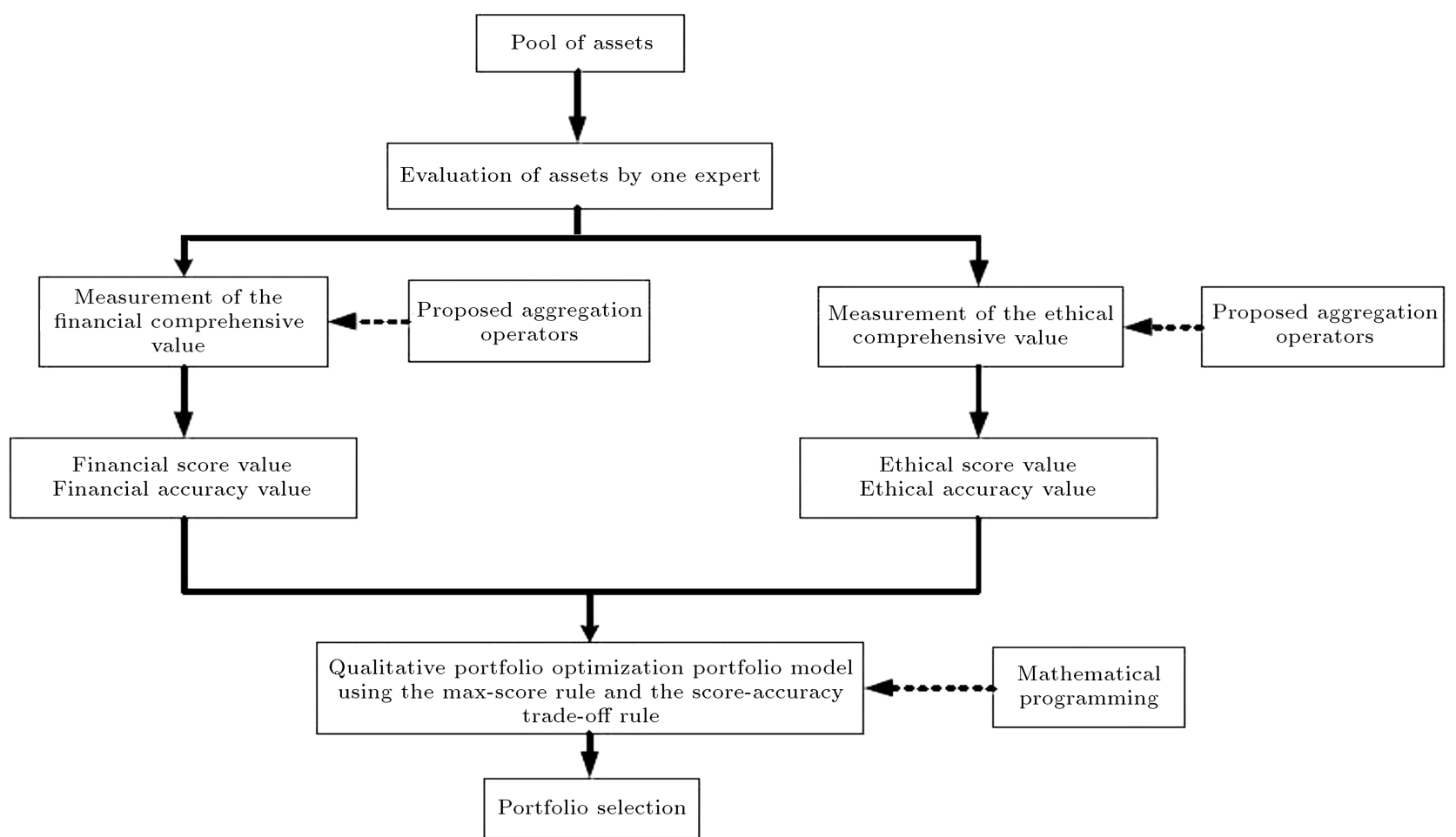

Figure 1. Typical flowchart for the ethical-financial portfolio selection based on the linguistic $Z$-number aggregation operators.

and financial criteria are separately aggregated using the proposed aggregation operators, and their score and accuracy values are computed. Finally, three qualitative portfolio selection models are developed based on the expert's opinions and investor's preferences in the third stage.

\subsection{The first stage: Ethical and financial assessment of assets}

Assume that there are $n$ risky assets as $\left\{x_{1}, x_{2}, \ldots, x_{n}\right\}$ to which investors can devote their capital. These assets are separately evaluated by the expert based on $m$ qualitative financial criteria $\left\{f_{1}, f_{2}, \ldots, f_{m}\right\}$ and $r$ qualitative ethical criteria $\left\{e_{1}, e_{2}, \ldots, e_{r}\right\}$. The evaluation information is expressed through the LZNs as $z_{i j}^{f}$ and $z_{i k}^{e}(i=1, \ldots, n, j=1, \ldots, m$ and $k=1, \ldots, r)$, respectively. In addition, it can be represented as two LZN matrices $Z^{f}=\left[z_{i j}^{f}\right]_{n \times m}$ and $Z^{e}=\left[z_{i k}^{e}\right]_{n \times r}$.

\subsection{The second stage: Computing the comprehensive value of each asset and its corresponding score and accuracy values}

In this stage, the financial and ethical comprehensive values of each asset are separately obtained based on the proposed aggregation operators $\bar{z}_{i}^{f}=$ $\left(\bar{A}_{\phi(i)}^{f}, \bar{B}_{\varphi(i)}^{f}\right)$ and $\bar{z}_{i}^{e}=\left(\bar{A}_{\phi(i)}^{e}, \bar{B}_{\varphi(i)}^{e}\right)(i=1, \ldots, n)$, respectively. The aggregated values are calculated using the proposed aggregation operators, as shown below:

$$
\begin{aligned}
& \bar{z}_{i}^{f}=L Z M M^{p}\left(z_{i 1}^{f}, \ldots, z_{i m}^{f}\right), \\
& \bar{z}_{i}^{e}=L Z M M^{p}\left(z_{i 1}^{e}, \ldots, z_{i k}^{e}\right)
\end{aligned}
$$

or:

$$
\begin{aligned}
& \bar{z}_{i}^{f}=L Z W M M^{p}\left(z_{i 1}^{f}, \ldots, z_{i m}^{f}\right), \\
& \bar{z}_{i}^{e}=L Z W M M^{p}\left(z_{i 1}^{e}, \ldots, z_{i k}^{e}\right),
\end{aligned}
$$

or:

$$
\begin{aligned}
& \bar{z}_{i}^{f}=L Z D M M^{p}\left(z_{i 1}^{f}, \ldots, z_{i m}^{f}\right), \\
& \bar{z}_{i}^{e}=L Z D M M^{p}\left(z_{i 1}^{e}, \ldots, z_{i k}^{e}\right),
\end{aligned}
$$

or:

$$
\begin{aligned}
& \bar{z}_{i}^{f}=L Z D W M M^{p}\left(z_{i 1}^{f}, \ldots, z_{i m}^{f}\right), \\
& \bar{z}_{i}^{e}=L Z D W M M^{p}\left(z_{i 1}^{e}, \ldots, z_{i k}^{e}\right) .
\end{aligned}
$$

Consequently, two LZN matrices $Z^{f}=\left[z_{i j}^{f}\right]_{n \times m}$ and $Z^{e}=\left[z_{i k}^{e}\right]_{n \times r}$ are transformed into two qualitative column vectors $\bar{Z}^{f}=\left[\bar{z}_{i}^{f}\right]_{n \times 1}$ and $\bar{Z}^{e}=\left[\bar{z}_{i}^{e}\right]_{n \times 1}$ by fusing all financial LZNs and all ethical LZNs on one line, respectively. Then, the values of financial score, financial accuracy, ethical score, and ethical accuracy 
are separately obtained based on Definition 5 , as shown in the following:

$$
\begin{aligned}
& S\left(\bar{z}_{i}^{f}\right)=f^{*}\left(\bar{A}_{\phi(i)}^{f}\right) \times g^{*}\left(\bar{B}_{\varphi(i)}^{f}\right), \\
& A\left(\bar{z}_{i}^{f}\right)=f^{*}\left(\bar{A}_{\phi(i)}^{f}\right) \times\left(1-g^{*}\left(\bar{B}_{\varphi(i)}^{f}\right)\right), \\
& S\left(\bar{z}_{i}^{e}\right)=f^{*}\left(\bar{A}_{\phi(i)}^{e}\right) \times g^{*}\left(\bar{B}_{\varphi(i)}^{e}\right), \\
& A\left(\bar{z}_{i}^{e}\right)=f^{*}\left(\bar{A}_{\phi(i)}^{e}\right) \times\left(1-g^{*}\left(\bar{B}_{\varphi(i)}^{e}\right)\right) .
\end{aligned}
$$

The obtained values can be represented as fourcolumn vectors:

$$
\begin{aligned}
& S^{f}=\left[S\left(\bar{z}_{i}^{f}\right)\right]_{n \times 1}, \quad A^{f}=\left[A\left(\bar{z}_{i}^{f}\right)\right]_{n \times 1}, \\
& S^{e}=\left[S\left(\bar{z}_{i}^{e}\right)\right]_{n \times 1}, \quad A^{e}=\left[A\left(\bar{z}_{i}^{e}\right)\right]_{n \times 1} .
\end{aligned}
$$

\subsection{The third stage: Portfolio selection based on aggregation operators in a $L Z N$ environment}

In this stage, three qualitative portfolio models are proposed to allocate the optimal assets. These models are considered as the alternative procedures of constructing more diversified portfolios based on a tradeoff between the ethical and financial criteria. In the proposed optimization models, the diversification of portfolio can be handled considering the lower and upper bounds of the capital budget portion in each asset along with a predefined number of assets assigned to the selected portfolio. Moreover, the portfolios can be selected based on the financial goal as the objective function and ethical goal as the constraint. In addition, they are selected based on a bi-objective optimization model. Furthermore, the trade-off among the financial and ethical criteria is tested using a biobjective optimization portfolio model along with an admissible accuracy level of portfolio as a risk constraint. In this study, these three circumstances were taken into consideration to formulate the qualitative portfolio models. Hong and Choi [62] illustrated that the relation between the score and accuracy functions was equivalent to that between the mean and variance of the quantitative information in the statistics. In this regard, the score and accuracy values were employed to measure the expected return and risk values of the portfolios in a LZN environment. In the following, three qualitative portfolio selection models are formulated based on the max-score and score-accuracy tradeoff rules. To this end, first, the objective function and constraints, which are common in all the three proposed qualitative portfolio models, are introduced as follows:

\section{- Objective function (financial goal)}

The financial objective function based on the maxscore rule is defined as follows:

$$
\begin{aligned}
\operatorname{Max} & \sum_{i=1}^{n}\left(\left(S\left(\bar{z}_{i}^{f}\right)\right) x_{i}\right)=\sum_{i=1}^{n}\left(\left(f^{*}\left(\bar{A}_{\phi(i)}^{f}\right)\right.\right. \\
& \left.\left.\times g^{*}\left(\bar{B}_{\varphi(i)}^{f}\right)\right) x_{i}\right) .
\end{aligned}
$$

\section{- Constraints:}

$$
\begin{aligned}
& \sum_{i=1}^{s} x_{i}=1 \\
& \sum_{i=1}^{s} y_{i}=h \\
& l_{i} y_{i} \leq x_{i} \leq u_{i} y_{i}, \quad i=1, \ldots, s \\
& y_{i} \in\{0,1\}, \quad i=1, \ldots, s \\
& x_{i} \geq 0, \quad i=1, \ldots, s .
\end{aligned}
$$

Constraint (28) is the budget constraint. Constraint (29), called the cardinality constraint, guarantees that the portfolio is confined to preserve a predefined number of assets such as $h$. Here, $l_{i}(\geq 0)$ is the minimum fraction of the total capital to be invested in the $i$ th asset, and $u_{i}\left(0 \leq l_{i} \leq u_{i}\right)$ the maximum fraction of the total investment to be assigned to the $i$ th asset. Assume that $x_{i}$ is the weight of the $i$ th asset in the portfolio and $y_{i}$ is the binary variable equal to one when the corresponding asset is allocated to the portfolio; otherwise, it is zero. Eventually, Constraint (32) shows the prohibition of short selling.

Here, three hybrid optimization models are proposed. The first two models (Models 1 and 2) are formulated based on the max-score rule. These proposed models can be used in situations where the investors aim to obtain the maximum financial goal with a desirable ethical level. Therefore, the first two models are appropriate for general socially responsible investors. Similarly, the third model (Model 3) is formulated based on the score-accuracy trade-off rule. This model can be used when the investors wish to obtain both the maximum financial and ethical goals with an admissible accuracy level as the risk of portfolio. Therefore, the third model is suitable for the risky socially responsible investors.

\subsubsection{Model 1: The portfolio selection optimization model}

To combine the ethical criteria with the portfolio selection problem, an ethical constraint is added to this model, as shown in the following.

\section{- Ethical constraint}

If investors or fund managers specify a desirable level for the ethical performance of the portfolio, an ethical constraint can be added to the portfolio selection model. The ethical constraint is formulated 
based on the max-score rule, as shown below:

$$
\begin{gathered}
\sum_{i=1}^{n}\left(\left(S\left(\bar{z}_{i}^{e}\right)\right) x_{i}\right)=\sum_{i=1}^{n}\left(\left(f^{*}\left(\bar{A}_{\phi(i)}^{e}\right)\right.\right. \\
\left.\left.\times g^{*}\left(\bar{B}_{\varphi(i)}^{e}\right)\right) x_{i}\right) \geq \gamma,
\end{gathered}
$$

where $\gamma \in\left[0, \max _{1 \leq i \leq n}\left(S\left(\bar{z}_{i}^{e}\right)\right)\right]$ is the minimum desirable level of the ethical performance of the portfolio determined by the investors. Three cases may show up while determining the desirable ethical level $\gamma$ :

1. If $\gamma>\max _{1 \leq i \leq n}\left(S\left(\bar{z}_{i}^{e}\right)\right)$, no portfolio is constructed because no feasible solution can be found;

2. If $\gamma=\max _{1 \leq i \leq n}\left(S\left(\bar{z}_{i}^{e}\right)\right)$, only one portfolio can be generated;

3. If $0 \leq \gamma \leq \max _{1 \leq i \leq n}\left(S\left(\bar{z}_{i}^{e}\right)\right)$, the greater the $\gamma$, the greater the effect of the desirable ethical level in the portfolio performance, and vice versa.

The portfolio selection optimization model (Model 1) can be formulated as follows:

Model 1:

$$
\begin{aligned}
\operatorname{Max} & \sum_{i=1}^{n}\left(\left(S\left(\bar{z}_{i}^{f}\right)\right) x_{i}\right) \\
& =\sum_{i=1}^{n}\left(\left(f^{*}\left(\bar{A}_{\phi(i)}^{f}\right) \times g^{*}\left(\bar{B}_{\varphi(i)}^{f}\right)\right) x_{i}\right)
\end{aligned}
$$

s.t.: Constraints (28)-(33).

Model 1 is usually employed by the general socially responsible investors when they aim to obtain the maximum financial goal with the desirable ethical level $\gamma$.

\subsubsection{Model 2: The portfolio selection optimization model}

When investors or fund managers decide to choose their portfolios based on the maximization of both financial and ethical performances simultaneously, they employ a bi-objective portfolio optimization model. In this regard, Model 2 can be formulated based on both financial and ethical criteria as follows:

Model 2:

$$
\begin{aligned}
& \operatorname{Max} \sum_{i=1}^{n}\left(\left(S\left(\bar{z}_{i}^{f}\right)\right) x_{i}\right) \\
& \quad=\sum_{i=1}^{n}\left(\left(f^{*}\left(\bar{A}_{\phi(i)}^{f}\right) \times g^{*}\left(\bar{B}_{\varphi(i)}^{f}\right)\right) x_{i}\right), \\
& \operatorname{Max} \sum_{i=1}^{n}\left(\left(S\left(\bar{z}_{i}^{e}\right)\right) x_{i}\right)=\sum_{i=1}^{n}\left(\left(f^{*}\left(\bar{A}_{\phi(i)}^{e}\right)\right.\right. \\
& \left.\left.\quad \times g^{*}\left(\bar{B}_{\varphi(i)}^{e}\right)\right) x_{i}\right)
\end{aligned}
$$

s.t.: Constraints $(28)-(32)$.

Model 2 is usually used by the general socially responsible investors who aim to obtain both the maximum financial and ethical goals simultaneously.

\subsubsection{Model 3: The portfolio selection optimization model}

Subsection 4.3 .2 presents a bi-objective qualitative portfolio optimization model based on the max-score rule in a LZN environment. As mentioned earlier, this model is suitable for the general socially responsible investors as they want to simultaneously maximize both financial and ethical goals in the selected portfolio. Hence, we can further extend these models using the score-accuracy trade-off rule. Obviously, this extended qualitative portfolio model is employed by the risky socially responsible investors as they wish to fulfill both maximum financial and maximum ethical goals along with an admissible accuracy level as the portfolio risk in the investment processes. This subsection formulates a bi-objective qualitative portfolio optimization model (Model 3) for the risky socially responsible investors based on the score-accuracy trade-off rule in a LZN environment. In order for the risky socially responsible investors to obtain the optimal portfolio, Model 3 is formulated as follows:

Model 3:

$$
\begin{aligned}
& \operatorname{Max} \sum_{i=1}^{n}\left(\left(S\left(\bar{z}_{i}^{f}\right)\right) x_{i}\right) \\
&=\sum_{i=1}^{n}\left(\left(f^{*}\left(\bar{A}_{\phi(i)}^{f}\right) \times g^{*}\left(\bar{B}_{\varphi(i)}^{f}\right)\right) x_{i}\right), \\
& \operatorname{Max} \sum_{i=1}^{n}\left(\left(S\left(\bar{z}_{i}^{e}\right)\right) x_{i}\right)=\sum_{1}^{n}\left(\left(f^{*}\left(\bar{A}_{\phi(i)}^{e}\right)\right.\right. \\
&\left.\left.\quad \times g^{*}\left(\bar{B}_{\varphi(i)}^{e}\right)\right) x_{i}\right),
\end{aligned}
$$

s.t.:

$$
\begin{gathered}
\sum_{i=1}^{n}\left(\left(A\left(\bar{z}_{i}^{f}\right)\right) x_{i}\right)=\sum_{i=1}^{n}\left(\left(f^{*}\left(\bar{A}_{\phi(i)}^{f}\right)\right.\right. \\
\left.\left.\times\left(1-g^{*}\left(\bar{B}_{\varphi(i)}^{f}\right)\right)\right) x_{i}\right) \geq \delta, \\
\sum_{i=1}^{n}\left(\left(A\left(\bar{z}_{i}^{e}\right)\right) x_{i}\right)=\sum_{i=1}^{n}\left(\left(f^{*}\left(\bar{A}_{\phi(i)}^{e}\right)\right.\right. \\
\left.\left.\times\left(1-g^{*}\left(\bar{B}_{\varphi(i)}^{e}\right)\right)\right) x_{i}\right) \geq \varphi .
\end{gathered}
$$

Constraints (28)-(32).

$\delta \in\left[0, \max _{1 \leq i \leq n}\left(A\left(\bar{z}_{i}^{f}\right)\right)\right]$ is the minimum admissible level of the financial accuracy value, and $\varphi \in$ 
$\left[0, \max _{1 \leq i \leq n}\left(A\left(\bar{z}_{i}^{e}\right)\right)\right]$ the minimum admissible level of the ethical accuracy value. Both $\delta$ - and $\varphi$-values are determined by investors or fund managers. While determining the $\delta$ - and $\varphi$-values, three cases may show up:

1. If $\delta>\max _{1 \leq i \leq n}\left(A\left(\bar{z}_{i}^{f}\right)\right)$ and $\varphi>\max _{1 \leq i \leq n}$ $\left(A\left(\bar{z}_{i}^{e}\right)\right)$, no portfolio is constructed because no feasible solution can be found;

2. If $\delta=\max _{1 \leq i \leq n}\left(A\left(\bar{z}_{i}^{f}\right)\right)$ and $\varphi=\max _{1 \leq i \leq n}$ $\left(A\left(\bar{z}_{i}^{e}\right)\right)$, only one portfolio can be generated;

3. If $0 \leq \delta \leq \max _{1 \leq i \leq n}\left(A\left(\bar{z}_{i}^{f}\right)\right)$ and $0 \leq \varphi \leq$ $\max _{1 \leq i \leq n}\left(A\left(\bar{z}_{i}^{e}\right)\right)$, the greater the $\delta$-value, the greater the effect of admissible level of the financial accuracy value in the portfolio performance. Similarly, the greater the $\varphi$-value, the greater the effect of admissible level of the ethical accuracy value in the portfolio performance.

\section{Case study and computational results}

In this section, Thomson Reuters ASSET database is used as the information source. It provides the standardized and simplified ESG information that covers over 6000 companies and involves 400 ESG metrics. Serval researchers including Miras-Rodríguez et al. [63], Ferrero-Ferrero et al. [64], and EscrigOlmedo et al. [65] applied Thomson Reuters ASSET database in their studies. Thomson Reuters suggests an ESG score to measure the ESG performance of each company based on its published data and categorizes the criteria into 10 topics within three groups that include social performance (workforce, human rights, community, and product responsibility), environmental performance (resource use, emissions, and innovation), and corporate governance performance (management, shareholders, and CSR strategy). In order to examine the proposed qualitative framework, this study applies the information available in the ESG database from September 2018 for the water and other utility industry companies. This example includes 20 listed firms.

\subsection{The first stage: $E S G$ and financial assessment of assets}

The Thomson Reuters database contains the criteria necessary for each foresaid domain. However, there are different restrictions such as the balancing of scores among the domains [64]. Therefore, the Thomson Reuters information can be used as the input of a fuzzy system in order to evaluate ESG and financial criteria [64]. In this stage, to better represent the intricate concepts, the given linguistic variables in Tables 1-4 [64] are employed to evaluate the performance of each asset with respect to the ESG and financial criteria. Further, the experts' experience and knowledge can efficiently be indicated by fuzzy if-then rules [66]. In this regard, these rules were utilized in this study to better evaluate the performance of firms with respect to the ethical and financial criteria based on the linguistic variables.

This study was conducted based on the assumption that investors aim to compare these 20 firms in terms of their performance based on four financial criteria namely Short-Term Returns (STR), LongTerm Returns (LTR), External Reputation (ER), and

Table 4. Linguistic variables for evaluating the financial performance of the firms $\left(T_{f}\right)$.

\begin{tabular}{ll} 
Very Very Low (VVL) & Almost High (AH) \\
Very Low (VL) & High $(\mathrm{H})$ \\
Low (L) & Very High (VH) \\
Almost Medium (AM) & Perfect (P) \\
Medium (M) & \\
\hline
\end{tabular}

Table 1. Linguistic variables for evaluating the social performance of the firms $\left(T_{s}\right)$.

\begin{tabular}{ll}
\hline Poor Social Performance (PSP) & High Social Performance (HSP) \\
Low Social Performance (LSP) & Top Social Performance (TSP) \\
Medium Social Performance (MSP) & \\
\hline
\end{tabular}

Table 2. Linguistic variables for evaluating the environmental performance of the firms $\left(T_{e}\right)$.

\begin{tabular}{ll}
\hline Poor Environmental Performance (PEP) & High Environmental Performance (HEP) \\
Low Environmental Performance (LEP) & Top Environmental Performance (TEP) \\
Medium Environmental Performance (MEP) & \\
\hline
\end{tabular}

Table 3. Linguistic variables for evaluating the corporate governance performance of the firms $\left(T_{g}\right)$.

\begin{tabular}{ll}
\hline Poor Corporate Governance Performance (PCGP) & High Corporate Governance Performance (HCGP) \\
Low Corporate Governance Performance (LCGP) & Top Corporate Governance Performance (TCGP) \\
Medium Corporate Governance Performance (MCGP) & \\
\hline
\end{tabular}


Table 5. Linguistic variables for evaluating the experts' reliability $\left(T^{\prime}\right)$.

\begin{tabular}{ll}
\hline Seldom (S) & Regularly (R) \\
Occasionally (O) & Usually (U) \\
Frequently (F) & \\
\hline
\end{tabular}

Liquidity (L) and to evaluate their performance based on the Environmental (E), Social (S), and corporate Governance $(\mathrm{G})$ criteria. Then, one expert evaluates the performance of each firm considering the mentioned criteria, and his/her opinions are captured using the linguistic terms provided in Tables $1-5$. To be specific, the linguistic term sets $T_{s}=\left\{t_{0}^{s}, t_{1}^{s}, t_{2}^{s}, t_{3}^{s}, t_{4}^{s}\right\}$, $T_{e}=\left\{t_{0}^{e}, t_{1}^{e}, t_{2}^{e}, t_{3}^{e}, t_{4}^{e}\right\}$, and $T_{g}=\left\{t_{0}^{g}, t_{1}^{g}, t_{2}^{g}, t_{3}^{g}, t_{4}^{g}\right\}$, shown in Tables 1-3, are used to evaluate the performances of these firms based on the social, environmental, and corporate governance criteria, respectively. In addition, the linguistic terms set $T_{f}=$ $\left\{t_{0}^{f}, t_{1}^{f}, t_{2}^{f}, t_{3}^{f}, t_{4}^{f}, t_{5}^{f}, t_{6}^{f}, t_{7}^{f}, t_{8}^{f}\right\}$, given in Table 4 , can be employed to evaluate the performance of firms in terms of their financial criteria. Moreover, the linguistic terms set $T^{\prime}=\left\{t_{0}^{\prime}, t_{1}^{\prime}, t_{2}^{\prime}, t_{3}^{\prime}, t_{4}^{\prime}\right\}$, given in Table 5 , is used to determine the reliability measure of the related information.

An expert evaluates the performance of the as- sets $\left\{x_{1}, x_{2}, \ldots, x_{20}\right\}$ based on both financial criteria $\left\{f_{1}, f_{2}, f_{3}, f_{4}\right\}=\{S T R, L T R, E R, L\}$ and ethical criteria $\left\{e_{1}, e_{2}, e_{3}\right\}=\{E, S, G\}$. The assessment information is represented by the LZNs as $z_{i j}^{f}$ and $z_{i k}^{e}(i=$ $1, \ldots, 20, j=1,2,3,4$, and $k=1,2,3)$ and then, two LZN matrices $Z^{f}=\left[z_{i j}^{f}\right]_{20 \times 4}$ and $Z^{e}=\left[z_{i k}^{e}\right]_{20 \times 3}$ are generated based on the $z_{i j}^{f}$ and $z_{i k}^{e}$. These matrices characterize the performance of assets regarding the financial criteria as well as the ESG criteria, the results of which are shown in Tables 6 and 7 , respectively. This information used to evaluate the performance of each firm based on the mentioned criteria simulates the expert's opinions and decision-maker's preferences. Therefore, the performance of the proposed models as a qualitative technique for combining the priorities of each decision-maker or investor in the asset allocation process is examined.

\subsection{The second stage: Calculating the comprehensive value of each asset and its corresponding score and accuracy values}

In this stage, two linguistic $Z$-number matrices $Z^{f}=$ $\left[z_{i j}^{f}\right]_{20 \times 4}$ and $Z^{e}=\left[z_{i k}^{e}\right]_{20 \times 3}$ are transformed into two qualitative column vectors $\bar{Z}^{f}=\left[\bar{z}_{i}^{f}\right]_{20 \times 1}$ and

Table 6. The evaluation data of assets relative to financial criteria expressed by LZNs.

\begin{tabular}{|c|c|c|c|c|c|c|c|c|c|}
\hline $\begin{array}{c}\text { Asset } \\
\text { ID }\end{array}$ & $\begin{array}{c}\text { Short-term } \\
\text { return }\end{array}$ & $\begin{array}{c}\text { Long-term } \\
\text { return }\end{array}$ & $\begin{array}{c}\text { External } \\
\text { reputation }\end{array}$ & Liquidity & $\begin{array}{c}\text { Asset } \\
\text { ID }\end{array}$ & $\begin{array}{c}\text { Short-term } \\
\text { return }\end{array}$ & $\begin{array}{c}\text { Long-term } \\
\text { return }\end{array}$ & $\begin{array}{c}\text { External } \\
\text { reputation }\end{array}$ & Liquidity \\
\hline 1 & $\left(t_{6}^{f}, t_{3}^{\prime}\right)$ & $\left(t_{5}^{f}, t_{4}^{\prime}\right)$ & $\left(t_{4}^{f}, t_{3}^{\prime}\right)$ & $\left(t_{5}^{f}, t_{4}^{\prime}\right)$ & 11 & $\left(t_{5}^{f}, t_{1}^{\prime}\right)$ & $\left(t_{3}^{f}, t_{4}^{\prime}\right)$ & $\left(t_{5}^{f}, t_{4}^{\prime}\right)$ & $\left(t_{6}^{f}, t_{1}^{\prime}\right)$ \\
\hline 2 & $\left(t_{7}^{f}, t_{3}^{\prime}\right)$ & $\left(t_{4}^{f}, t_{4}^{\prime}\right)$ & $\left(t_{2}^{f}, t_{3}^{\prime}\right)$ & $\left(t_{6}^{f}, t_{3}^{\prime}\right)$ & 12 & $\left(t_{1}^{f}, t_{1}^{\prime}\right)$ & $\left(t_{3}^{f}, t_{2}^{\prime}\right)$ & $\left(t_{5}^{f}, t_{3}^{\prime}\right)$ & $\left(t_{5}^{f}, t_{1}^{\prime}\right)$ \\
\hline 3 & $\left(t_{5}^{f}, t_{1}^{\prime}\right)$ & $\left(t_{3}^{f}, t_{2}^{\prime}\right)$ & $\left(t_{6}^{f}, t_{3}^{\prime}\right)$ & $\left(t_{5}^{f}, t_{2}^{\prime}\right)$ & 13 & $\left(t_{6}^{f}, t_{2}^{\prime}\right)$ & $\left(t_{5}^{f}, t_{3}^{\prime}\right)$ & $\left(t_{2}^{f}, t_{4}^{\prime}\right)$ & $\left(t_{5}^{f}, t_{3}^{\prime}\right)$ \\
\hline 4 & $\left(t_{2}^{f}, t_{4}^{\prime}\right)$ & $\left(t_{4}^{f}, t_{3}^{\prime}\right)$ & $\left(t_{6}^{f}, t_{4}^{\prime}\right)$ & $\left(t_{3}^{f}, t_{3}^{\prime}\right)$ & 14 & $\left(t_{6}^{f}, t_{4}^{\prime}\right)$ & $\left(t_{4}^{f}, t_{3}^{\prime}\right)$ & $\left(t_{4}^{f}, t_{4}^{\prime}\right)$ & $\left(t_{5}^{f}, t_{3}^{\prime}\right)$ \\
\hline 5 & $\left(t_{3}^{f}, t_{2}^{\prime}\right)$ & $\left(t_{1}^{f}, t_{2}^{\prime}\right)$ & $\left(t_{5}^{f}, t_{3}^{\prime}\right)$ & $\left(t_{5}^{f}, t_{1}^{\prime}\right)$ & 15 & $\left(t_{5}^{f}, t_{1}^{\prime}\right)$ & $\left(t_{2}^{f}, t_{4}^{\prime}\right)$ & $\left(t_{6}^{f}, t_{4}^{\prime}\right)$ & $\left(t_{2}^{f}, t_{3}^{\prime}\right)$ \\
\hline 6 & $\left(t_{4}^{f}, t_{4}^{\prime}\right)$ & $\left(t_{5}^{f}, t_{2}^{\prime}\right)$ & $\left(t_{4}^{f}, t_{3}^{\prime}\right)$ & $\left(t_{4}^{f}, t_{2}^{\prime}\right)$ & 16 & $\left(t_{7}^{f}, t_{4}^{\prime}\right)$ & $\left(t_{3}^{f}, t_{4}^{\prime}\right)$ & $\left(t_{4}^{f}, t_{3}^{\prime}\right)$ & $\left(t_{5}^{f}, t_{3}^{\prime}\right)$ \\
\hline 7 & $\left(t_{7}^{f}, t_{3}^{\prime}\right)$ & $\left(t_{5}^{f}, t_{4}^{\prime}\right)$ & $\left(t_{3}^{f}, t_{4}^{\prime}\right)$ & $\left(t_{6}^{f}, t_{3}^{\prime}\right)$ & 17 & $\left(t_{4}^{f}, t_{4}^{\prime}\right)$ & $\left(t_{6}^{f}, t_{3}^{\prime}\right)$ & $\left(t_{5}^{f}, t_{2}^{\prime}\right)$ & $\left(t_{6}^{f}, t_{4}^{\prime}\right)$ \\
\hline 8 & $\left(t_{3}^{f}, t_{4}^{\prime}\right)$ & $\left(t_{4}^{f}, t_{3}^{\prime}\right)$ & $\left(t_{5}^{f}, t_{3}^{\prime}\right)$ & $\left(t_{3}^{f}, t_{4}^{\prime}\right)$ & 18 & $\left(t_{5}^{f}, t_{1}^{\prime}\right)$ & $\left(t_{3}^{f}, t_{2}^{\prime}\right)$ & $\left(t_{5}^{f}, t_{4}^{\prime}\right)$ & $\left(t_{1}^{f}, t_{4}^{\prime}\right)$ \\
\hline 9 & $\left(t_{7}^{f}, t_{4}^{\prime}\right)$ & $\left(t_{6}^{f}, t_{3}^{\prime}\right)$ & $\left(t_{4}^{f}, t_{4}^{\prime}\right)$ & $\left(t_{7}^{f}, t_{4}^{\prime}\right)$ & 19 & $\left(t_{3}^{f}, t_{4}^{\prime}\right)$ & $\left(t_{7}^{f}, t_{2}^{\prime}\right)$ & $\left(t_{2}^{f}, t_{2}^{\prime}\right)$ & $\left(t_{6}^{f}, t_{3}^{\prime}\right)$ \\
\hline 10 & $\left(t_{3}^{f}, t_{4}^{\prime}\right)$ & $\left(t_{2}^{f}, t_{2}^{\prime}\right)$ & $\left(t_{6}^{f}, t_{3}^{\prime}\right)$ & $\left(t_{4}^{f}, t_{1}^{\prime}\right)$ & 20 & $\left(t_{1}^{f}, t_{4}^{\prime}\right)$ & $\left(t_{3}^{f}, t_{3}^{\prime}\right)$ & $\left(t_{7}^{f}, t_{3}^{\prime}\right)$ & $\left(t_{2}^{f}, t_{2}^{\prime}\right)$ \\
\hline
\end{tabular}


Table 7. The evaluation data of assets relative to ESG criteria expressed by LZNs.

\begin{tabular}{cccccccc}
\hline Asset ID & Social & Environmental & Governance & Asset ID & Social & Environmental & Governance \\
\hline 1 & $\left(t_{4}^{s}, t_{3}^{\prime}\right)$ & $\left(t_{4}^{e}, t_{4}^{\prime}\right)$ & $\left(t_{3}^{g}, t_{2}^{\prime}\right)$ & 11 & $\left(t_{3}^{s}, t_{2}^{\prime}\right)$ & $\left(t_{2}^{e}, t_{2}^{\prime}\right)$ & $\left(t_{2}^{g}, t_{1}^{\prime}\right)$ \\
2 & $\left(t_{3}^{s}, t_{3}^{\prime}\right)$ & $\left(t_{4}^{e}, t_{3}^{\prime}\right)$ & $\left(t_{3}^{g}, t_{1}^{\prime}\right)$ & 12 & $\left(t_{3}^{s}, t_{2}^{\prime}\right)$ & $\left(t_{4}^{e}, t_{3}^{\prime}\right)$ & $\left(t_{4}^{g}, t_{3}^{\prime}\right)$ \\
3 & $\left(t_{2}^{s}, t_{3}^{\prime}\right)$ & $\left(t_{1}^{e}, t_{3}^{\prime}\right)$ & $\left(t_{3}^{g}, t_{3}^{\prime}\right)$ & 13 & $\left(t_{2}^{s}, t_{2}^{\prime}\right)$ & $\left(t_{2}^{e}, t_{3}^{\prime}\right)$ & $\left(t_{3}^{g}, t_{1}^{\prime}\right)$ \\
4 & $\left(t_{4}^{s}, t_{3}^{\prime}\right)$ & $\left(t_{3}^{e}, t_{3}^{\prime}\right)$ & $\left(t_{4}^{g}, t_{4}^{\prime}\right)$ & 14 & $\left(t_{4}^{s}, t_{4}^{\prime}\right)$ & $\left(t_{3}^{e}, t_{1}^{\prime}\right)$ & $\left(t_{3}^{g}, t_{1}^{\prime}\right)$ \\
5 & $\left(t_{2}^{s}, t_{2}^{\prime}\right)$ & $\left(t_{3}^{e}, t_{2}^{\prime}\right)$ & $\left(t_{4}^{g}, t_{3}^{\prime}\right)$ & 15 & $\left(t_{2}^{s}, t_{3}^{\prime}\right)$ & $\left(t_{3}^{e}, t_{3}^{\prime}\right)$ & $\left(t_{3}^{g}, t_{1}^{\prime}\right)$ \\
6 & $\left(t_{3}^{s}, t_{2}^{\prime}\right)$ & $\left(t_{4}^{e}, t_{3}^{\prime}\right)$ & $\left(t_{3}^{g}, t_{1}^{\prime}\right)$ & 16 & $\left(t_{4}^{s}, t_{3}^{\prime}\right)$ & $\left(t_{3}^{e}, t_{2}^{\prime}\right)$ & $\left(t_{4}^{g}, t_{4}^{\prime}\right)$ \\
7 & $\left(t_{3}^{s}, t_{1}^{\prime}\right)$ & $\left(t_{1}^{e}, t_{4}^{\prime}\right)$ & $\left(t_{3}^{g}, t_{3}^{\prime}\right)$ & 17 & $\left(t_{3}^{s}, t_{1}^{\prime}\right)$ & $\left(t_{3}^{e}, t_{1}^{\prime}\right)$ & $\left(t_{3}^{g}, t_{3}^{\prime}\right)$ \\
8 & $\left(t_{4}^{s}, t_{4}^{\prime}\right)$ & $\left(t_{0}^{e}, t_{4}^{\prime}\right)$ & $\left(t_{2}^{g}, t_{3}^{\prime}\right)$ & 18 & $\left(t_{1}^{s}, t_{4}^{\prime}\right)$ & $\left(t_{2}^{e}, t_{1}^{\prime}\right)$ & $\left(t_{1}^{g}, t_{3}^{\prime}\right)$ \\
9 & $\left(t_{0}^{s}, t_{4}^{\prime}\right)$ & $\left(t_{2}^{e}, t_{1}^{\prime}\right)$ & $\left(t_{2}^{g}, t_{2}^{\prime}\right)$ & 19 & $\left(t_{3}^{s}, t_{3}^{\prime}\right)$ & $\left(t_{2}^{e}, t_{2}^{\prime}\right)$ & $\left(t_{3}^{g}, t_{1}^{\prime}\right)$ \\
10 & $\left(t_{0}^{s}, t_{4}^{\prime}\right)$ & $\left(t_{3}^{e}, t_{1}^{\prime}\right)$ & $\left(t_{3}^{g}, t_{3}^{\prime}\right)$ & 20 & $\left(t_{3}^{s}, t_{3}^{\prime}\right)$ & $\left(t_{4}^{e}, t_{3}^{\prime}\right)$ & $\left(t_{3}^{g}, t_{2}^{\prime}\right)$ \\
\hline
\end{tabular}

$\bar{Z}^{e}=\left[\bar{z}_{i}^{e}\right]_{20 \times 1}$ by fusing all the financial LZNs with ESG linguistic $Z$-numbers on one line based on LZMM, LZWMM, LZDMM, and LZDWMM operators, respectively. Therefore, two qualitative vectors $\bar{Z}^{f}=$ $\left[\bar{z}_{i}^{f}\right]_{20 \times 1}$ and $\bar{Z}^{e}=\left[\bar{z}_{i}^{e}\right]_{20 \times 1}$, shown in Tables $8-11$, are calculated based on the LZMM, LZWMM, LZDMM, and LZDWMM operators, respectively. Then, the financial score, financial accuracy, ESG score, and ESG accuracy values are separately obtained through Definition 5 , and the results of which are listed in Tables 8-11.

According to Tables 8-11, if we consider only the financial criteria for calculating the score and accuracy values of assets, then assets are ranked according to their financial performance in a descending order, as shown below:

- LZMM operator

$$
\begin{aligned}
x_{9} & >x_{7}>x_{1}>x_{17}>x_{14}>x_{16}>x_{2}>x_{8} \\
& >x_{13}>x_{4}>x_{6}>x_{9}>x_{11}>x_{15}>x_{3} \\
& >x_{10}>x_{20}>x_{18}>x_{5}>x_{12}
\end{aligned}
$$

- LZWMM operator

$$
\begin{gathered}
x_{9}>x_{7}>x_{1}>x_{17}>x_{14}>x_{16}>x_{2}>x_{8} \\
>x_{13}>x_{4}>x_{6}>x_{9}>x_{11}>x_{15}>x_{3}
\end{gathered}
$$

$$
>x_{10}>x_{20}>x_{18}>x_{5}>x_{12}
$$

- LZDMM operator

$$
\begin{aligned}
x_{9} & >x_{7}>x_{1}>x_{17}>x_{14}>x_{16}>x_{2}>x_{4} \\
& >x_{8}>x_{13}>x_{19}>x_{6}>x_{11}>x_{15}>x_{3} \\
& >x_{10}>x_{20}>x_{18}>x_{5}>x_{12}
\end{aligned}
$$

- LZDWMM operator

$$
\begin{aligned}
x_{9} & >x_{7}>x_{1}>x_{16}>x_{14}>x_{17}>x_{2}>x_{4} \\
& >x_{8}>x_{13}>x_{19}>x_{6}>x_{15}>x_{11}>x_{3} \\
& >x_{20}>x_{10}>x_{18}>x_{5}>x_{12}
\end{aligned}
$$

As observed, some assets (such as 14 and 17 under LZMM operator; 14 and 17 under LZWMM operator; and 11 and 15 under LZDMM operator) have the same score values. Hence, they are ranked based on their accuracy values. Now, if we consider only the ESG criteria to calculate the score and accuracy values of assets, then the assets are ranked based on their ESG performance in a descending order, as shown below:

- LZMM operator

$$
\begin{gathered}
x_{4}>x_{1}>x_{16}>x_{12}>x_{20}>x_{8}>x_{2}>x_{5} \\
>x_{6}>x_{15}>x_{3}>x_{14}>x_{7}>x_{10}>x_{19}
\end{gathered}
$$


Table 8. The aggregated values and their corresponding score and accuracy values resulting from LZMM operator for $f^{*}\left(x_{i}\right)=L S F 1$ and $g^{*}\left(x_{i}\right)=L S F 1$.

\begin{tabular}{|c|c|c|c|c|c|c|c|}
\hline \multirow[b]{2}{*}{$\begin{array}{c}\text { Parameter } \\
\text { vector }\end{array}$} & \multirow[b]{2}{*}{$\begin{array}{c}\text { Asset } \\
\text { ID }\end{array}$} & \multicolumn{3}{|c|}{ Financial criteria } & \multicolumn{3}{|c|}{ ESG criteria } \\
\hline & & $\begin{array}{c}\text { Aggregated } \\
\text { value }\end{array}$ & $\begin{array}{l}\text { Score } \\
\text { value }\end{array}$ & $\begin{array}{c}\text { Accuracy } \\
\text { value }\end{array}$ & $\begin{array}{c}\text { Aggregated } \\
\text { value }\end{array}$ & $\begin{array}{l}\text { Score } \\
\text { value }\end{array}$ & $\begin{array}{c}\text { Accuracy } \\
\text { value }\end{array}$ \\
\hline & 1 & $\left(t_{9.898}^{f}, t_{3.464}^{\prime}\right)$ & 1.072 & 0.166 & $\left(t_{9.158}^{E S G}, t_{2.884}^{\prime}\right)$ & 1.651 & 0.638 \\
\hline & 2 & $\left(t_{9.476}^{f}, t_{2.912}^{\prime}\right)$ & 0.863 & 0.322 & $\left(t_{8.32}^{E S G}, t_{2.08}^{\prime}\right)$ & 1.082 & 0.998 \\
\hline & 3 & $\left(t_{9.211}^{f}, t_{1.861}^{\prime}\right)$ & 0.536 & 0.616 & $\left(t_{4.579}^{E S G}, t_{3}^{\prime}\right)$ & 0.859 & 0.286 \\
\hline & 4 & $\left(t_{6.928}^{f}, t_{3.464}^{\prime}\right)$ & 0.750 & 0.116 & $\left(t_{9.158}^{E S G}, t_{3.301}^{\prime}\right)$ & 1.890 & 0.400 \\
\hline & 5 & $\left(t_{5.885}^{f}, t_{1.861}^{\prime}\right)$ & 0.342 & 0.393 & $\left(t_{7.268}^{E S G}, t_{2.289}^{\prime}\right)$ & 1.040 & 0.777 \\
\hline & 6 & $\left(t_{8.458}^{f}, t_{2.632}^{\prime}\right)$ & 0.696 & 0.362 & $\left(t_{8.32}^{E S G}, t_{1.817}^{\prime}\right)$ & 0.945 & 1.135 \\
\hline & 7 & $\left(t_{10.019}^{f}, t_{3.464}^{\prime}\right)$ & 1.085 & 0.168 & $\left(t_{5.241}^{E S G}, t_{2.289}^{\prime}\right)$ & 0.750 & 0.560 \\
\hline & 8 & $\left(t_{7.325}^{f}, t_{3.464}^{\prime}\right)$ & 0.793 & 0.123 & $\left(t_{5.04}^{E S G}, t_{3.634}^{\prime}\right)$ & 1.145 & 0.115 \\
\hline & 9 & $\left(t_{11.712}^{f}, t_{3.722}^{\prime}\right)$ & 1.362 & 0.102 & $\left(t_{4}^{E S G}, t_{2}^{\prime}\right)$ & 0.500 & 0.500 \\
\hline$P^{f}=(0.25,0.25,0.25,0.25)$ & 10 & $\left(t_{6.928}^{f}, t_{2.213}^{\prime}\right)$ & 0.479 & 0.387 & $\left(t_{5.241}^{E S G}, t_{2.289}^{\prime}\right)$ & 0.750 & 0.560 \\
\hline \multirow[t]{10}{*}{$P^{E S G}=(0.33,0.33,0.33)$} & 11 & $\left(t_{9.211}^{f}, t_{2}^{\prime}\right)$ & 0.576 & 0.576 & $\left(t_{5.769}^{E S G}, t_{1.587}^{\prime}\right)$ & 0.572 & 0.870 \\
\hline & 12 & $\left.f_{.885}, t_{1.565}^{\prime}\right)$ & 0.287 & 0.447 & $\left(t_{9.158}^{E S G}, t_{2.62}^{\prime}\right)$ & 1.500 & 0.789 \\
\hline & 13 & $\left(t_{8.323}^{f}, t_{2.912}^{\prime}\right)$ & 0.758 & 0.283 & $\left(t_{5.769}^{E S G}, t_{1.817}^{\prime}\right)$ & 0.655 & 0.787 \\
\hline & 14 & $\left(t_{9.361}^{f}, t_{3.464}^{\prime}\right)$ & 1.013 & 0.157 & $\left(t_{8.32}^{E S G}, t_{1.587}^{\prime}\right)$ & 0.825 & 1.255 \\
\hline & 15 & $\left(t_{6.619}^{f}, t_{2.632}^{\prime}\right)$ & 0.544 & 0.283 & $\left(t_{6.604}^{E S G}, t_{2.08}^{\prime}\right)$ & 0.859 & 0.792 \\
\hline & 16 & $\left(t_{9.054}^{f}, t_{3.464}^{\prime}\right)$ & 0.980 & 0.152 & $\left(t_{9.158}^{E S G}, t_{2.884}^{\prime}\right)$ & 1.651 & 0.638 \\
\hline & 17 & $\left(t_{10.36}^{f}, t_{3.13}^{\prime}\right)^{\prime}$ & 1.013 & 0.282 & $\left(t_{7.56}^{E S G}, t_{1.442}^{\prime}\right)$ & 0.681 & 1.208 \\
\hline & 18 & $\left(t_{5.885}^{f}, t_{2.378}^{\prime}\right)$ & 0.437 & 0.298 & $\left(t_{3.175}^{E S G}, t_{2.289}^{\prime}\right)$ & 0.454 & 0.339 \\
\hline & 19 & $\left(t_{7.968}^{f}, t_{2.632}^{\prime}\right)$ & 0.655 & 0.341 & $\left(t_{6.604}^{E S G}, t_{1.817}^{\prime}\right)$ & 0.750 & 0.901 \\
\hline & 20 & $\left(t_{5.091}^{f}, t_{2.912}^{\prime}\right)$ & 0.463 & 0.173 & $\left(t_{8.32}^{E S G}, t_{2.62}^{\prime}\right)$ & 1.363 & 0.717 \\
\hline
\end{tabular}

$$
>x_{17}>x_{13}>x_{11}>x_{9}>x_{18}
$$

- LZWMM operator

$$
\begin{gathered}
x_{4}>x_{1}>x_{16}>x_{12}>x_{20}>x_{8}>x_{2}>x_{5} \\
>x_{6}>x_{15}>x_{3}>x_{14}>x_{19}>x_{7}>x_{10} \\
>x_{17}>x_{13}>x_{11}>x_{9}>x_{18}
\end{gathered}
$$

- LZDMM operator

$$
\begin{gathered}
x_{4}>x_{1}>x_{16}>x_{12}>x_{20}>x_{8}>x_{2}>x_{14} \\
>x_{5}>x_{6}>x_{15}>x_{3}>x_{19}>x_{7}>x_{10} \\
>x_{17}>x_{13}>x_{11}>x_{9}>x_{18}
\end{gathered}
$$

- LZDWMM operator

$$
\begin{aligned}
x_{4} & >x_{1}>x_{16}>x_{12}>x_{8}>x_{20}>x_{2}>x_{14}>x_{5} \\
& >x_{6}>x_{15}>x_{3}>x_{7}>x_{19}>x_{10}>x_{17} \\
& >x_{13}>x_{11}>x_{9}>x_{18}
\end{aligned}
$$

Obviously, the ranking based on the financial criteria is absolutely different from that based on the ESG criteria. For example, assets 7 and 9 always exhibit the best financial performance, while their ESG performance is poor. Therefore, we can use the main advantage of the proposed portfolio models and select the optimal assets based on a trade-off between the financial and ESG criteria according to the investor's preferences.

\subsection{The third stage: Portfolio selection based on aggregation operators under $L Z N$ environment}

In this step, the qualitative portfolio models are established based on Model 1, Model 2, and Model 3. These models can select the optimal combinations of assets by considering a trade-off among the financial and ESG criteria according to the investors' preferences. The parameters of the proposed models are $h=8, l_{i}=0.05$, and $u_{i}=0.5$. Clearly, the proposed models are mixed integer programming models. Speranza [67] indicated 
Table 9. The aggregated values and their corresponding score and accuracy values resulting from LZWMM operator for $f^{*}\left(x_{i}\right)=L S F 1, g^{*}\left(x_{i}\right)=L S F 1, w^{f}=(0.3,0.3,0.25,0.15)$, and $w^{E S G}=(0.4,0.3,0.3)$.

\begin{tabular}{|c|c|c|c|c|c|c|c|}
\hline \multirow[b]{2}{*}{$\begin{array}{c}\text { Parameter } \\
\text { vector }\end{array}$} & \multirow[b]{2}{*}{$\begin{array}{l}\text { Asset } \\
\text { ID }\end{array}$} & \multicolumn{3}{|c|}{ Financial criteria } & \multicolumn{3}{|c|}{ ESG criteria } \\
\hline & & $\begin{array}{c}\text { Aggregated } \\
\text { value }\end{array}$ & $\begin{array}{l}\text { Score } \\
\text { value }\end{array}$ & $\begin{array}{c}\text { Accuracy } \\
\text { value }\end{array}$ & $\begin{array}{c}\text { Aggregated } \\
\text { value }\end{array}$ & $\begin{array}{l}\text { Score } \\
\text { value }\end{array}$ & $\begin{array}{c}\text { Accuracy } \\
\text { value }\end{array}$ \\
\hline & 1 & $\left(t_{9.543}^{f}, t_{3.464}^{\prime}\right)$ & 1.033 & 0.160 & $\left(t_{7.205}^{E S G}, t_{2.884}^{\prime}\right)$ & 1.299 & 0.502 \\
\hline & 2 & $\left(t_{9.136}^{f}, t_{2.912}^{\prime}\right)$ & 0.832 & 0.310 & $\left(t_{6.546}^{E S G}, t_{2.08}^{\prime}\right)$ & 0.851 & 0.786 \\
\hline & 3 & $\left(t_{8.881}^{f}, t_{1.861}^{\prime}\right)$ & 0.517 & 0.594 & $\left(t_{3.602}^{E S G}, t_{3}^{\prime}\right)$ & 0.675 & 0.225 \\
\hline & 4 & $\left(t_{6.68}^{f}, t_{3.464}^{\prime}\right)$ & 0.723 & 0.112 & $\left(t_{7.205}^{E S G}, t_{3.301}^{\prime}\right)$ & 1.487 & 0.314 \\
\hline & 5 & $\left(t_{5.674}^{f}, t_{1.861}^{\prime}\right)$ & 0.330 & 0.379 & $\left(t_{5.719}^{E S G}, t_{2.289}^{\prime}\right)$ & 0.818 & 0.611 \\
\hline & 6 & $\left(t_{8.155}^{f}, t_{2.632}^{\prime}\right)$ & 0.671 & 0.349 & $\left(t_{6.546}^{E S G}, t_{1.817}^{\prime}\right)$ & 0.743 & 0.893 \\
\hline & 7 & $\left(t_{9.66}^{f}, t_{3.464}^{\prime}\right)$ & 1.046 & 0.162 & $\left(t_{4.124}^{E S G}, t_{2.289}^{\prime}\right)$ & 0.590 & 0.441 \\
\hline & 8 & $\left(t_{7.063}^{f}, t_{3.464}^{\prime}\right)$ & 0.765 & 0.118 & $\left(t_{3.965}^{E S G}, t_{3.634}^{\prime}\right)$ & 0.901 & 0.091 \\
\hline & 9 & $\left(t_{11.292}^{f}, t_{3.722}^{\prime}\right)$ & 1.314 & 0.098 & $\left(t_{3.147}^{E S G}, t_{2}^{\prime}\right)$ & 0.393 & 0.393 \\
\hline$P^{f}=(0.25,0.25,0.25,0.25)$ & 10 & $\left(t_{6.68}^{f}, t_{2.213}^{\prime}\right)$ & 0.462 & 0.373 & $\left(t_{4.124}^{E S G}, t_{2.289}^{\prime}\right)$ & 0.590 & 0.441 \\
\hline \multirow[t]{10}{*}{$P^{E S G}=(0.33,0.33,0.33)$} & 11 & $\left(t_{8.881}^{f}, t_{2}^{\prime}\right)$ & 0.555 & 0.555 & $\left(t_{4.539}^{E S G}, t_{1.587}^{\prime}\right)$ & 0.450 & 0.684 \\
\hline & 12 & $\left(t_{5.674}^{f}, t_{1.565}^{\prime}\right)$ & 0.278 & 0.432 & $\left(t_{7.205}^{E S G}, t_{2.62}^{\prime}\right)$ & 1.180 & 0.621 \\
\hline & 13 & $\left(t_{8.025}^{f}, t_{2.912}^{\prime}\right)$ & 0.731 & 0.273 & $\left(t_{4.539}^{E S G}, t_{1.817}^{\prime}\right)$ & 0.515 & 0.619 \\
\hline & 14 & $\left(t_{9.025}^{f}, t_{3.464}^{\prime}\right)$ & 0.977 & 0.151 & $\left(t_{6.546}^{E S G}, t_{1.587}^{\prime}\right)$ & 0.649 & 0.987 \\
\hline & 15 & $\left(t_{6.382}^{f}, t_{2.632}^{\prime}\right)$ & 0.525 & 0.273 & $\left(t_{5.194}^{E S G}, t_{2.08}^{\prime}\right)$ & 0.675 & 0.623 \\
\hline & 16 & $\left(t_{8.729}^{f}, t_{3.464}^{\prime}\right)$ & 0.945 & 0.146 & $\left(t_{7.205}^{E S G}, t_{2.884}^{\prime}\right)$ & 1.299 & 0.502 \\
\hline & 17 & $\left(t_{9.988}^{f}, t_{3.13}^{\prime}\right)$ & 0.977 & 0.272 & $\left(t_{5.948}^{E S G}, t_{1.442}^{\prime}\right)$ & 0.536 & 0.951 \\
\hline & 18 & $\left(t_{5.674}^{f}, t_{2.378}^{\prime}\right)$ & 0.422 & 0.288 & $\left(t_{2.498}^{E S G}, t_{2.289}^{\prime}\right)$ & 0.357 & 0.267 \\
\hline & 19 & $\left(t_{7.683}^{f}, t_{2.632}^{\prime}\right)$ & 0.632 & 0.328 & $\left(t_{5.196}^{E S G}, t_{1.817}^{\prime}\right)$ & 0.590 & 0.709 \\
\hline & 20 & $\left(t_{4.909}^{f}, t_{2.912}^{\prime}\right)$ & 0.447 & 0.167 & $\left(t_{6.546}^{E S G}, t_{2.62}^{\prime}\right)$ & 1.072 & 0.564 \\
\hline
\end{tabular}

that the computational complexity of the Mixed Integer Linear Programming (MILP) model depended on the number of integer and binary variables. He also proved that obtaining the optimal solutions for MILP models in a rational time was impossible in the case of the number of variables greater than 15 . In addition, Mansini and Speranza [68] proved that solving the portfolio selection model with round lots was NP-hard. Therefore, Genetic Algorithm (GA) was employed to solve Model 1, and the second version of Non-dominated Sorting Genetic Algorithm II (NSGAII) was used to solve Models 2 and 3. The parameters of GA and NSGA-II are adjusted as follows: $P O P_{\text {size }}$ of 100 , crossover rate of 0.8 , mutation rate of 0.4 , and maximum iteration of 500. In addition, GA and NSGAII were run 10 times for each case in MATLAB R2014a on a PC with Pentium(R) Dual core-CPU $2.0 \mathrm{GHz}$ Processor and 2 GB of RAM memory.

\section{- Asset allocation using Model 1}

In this case, $\gamma=0.5$ should be taken into account to establish Model 1 based on the four proposed aggregation operators. Then, Model 1 is solved based on $f^{*}\left(x_{i}\right)=L S F 1, g^{*}\left(x_{i}\right)=L S F 1, P^{f}=$ $(0.25,0.25,0.25,0.25), P^{E S G}=(0.33,0.33,0.33), w^{f}$ $(0.3,0.3,0.25,0.15)$, and $w^{E S G}(0.4,0.3,0.3)$. The selected portfolios are reported in Table 12. According to Figure 2, while using LZMM and LZWMM operators, the performance of asset 9 is better than that of the others. In addition, while using LZDMM and LZDWMM operators, more budget is allocated to assets 1, 4, and 16. All of these assets (1, 4, 9, and 16) have high financial score values and their ESG score values are placed within the admissible limits. Moreover, as observed, the portfolios selected based on the four proposed aggregation operators are slightly different. This difference is indicative 
Table 10. The aggregated values and their corresponding score and accuracy values resulting from LZDMM operator for $f^{*}\left(x_{i}\right)=L S F 1$ and $g^{*}\left(x_{i}\right)=L S F 1$.

\begin{tabular}{|c|c|c|c|c|c|c|c|}
\hline \multirow[b]{2}{*}{$\begin{array}{c}\text { Parameter } \\
\text { vector }\end{array}$} & \multirow[b]{2}{*}{$\begin{array}{c}\text { Asset } \\
\text { ID }\end{array}$} & \multicolumn{3}{|c|}{ Financial criteria } & \multicolumn{3}{|c|}{ ESG criteria } \\
\hline & & $\begin{array}{c}\text { Aggregated } \\
\text { value }\end{array}$ & $\begin{array}{l}\text { Score } \\
\text { value }\end{array}$ & $\begin{array}{c}\text { Accuracy } \\
\text { value }\end{array}$ & $\begin{array}{c}\text { Aggregated } \\
\text { value }\end{array}$ & $\begin{array}{l}\text { Score } \\
\text { value }\end{array}$ & $\begin{array}{c}\text { Accuracy } \\
\text { value }\end{array}$ \\
\hline & 1 & $\left(t_{3.125}^{f}, t_{3.063}^{\prime}\right)$ & 0.299 & 0.092 & $\left(t_{3.358}^{E S G}, t_{2.388}^{\prime}\right)$ & 0.501 & 0.338 \\
\hline & 2 & $\left(t_{3.125}^{f}, t_{2.326}^{\prime}\right)$ & 0.227 & 0.164 & $\left(t_{2.775}^{E S G}, t_{1.44}^{\prime}\right)$ & 0.250 & 0.444 \\
\hline & 3 & $\left(t_{2.82}^{f}, t_{1.053}^{\prime}\right)$ & 0.093 & 0.260 & $\left(t_{0.999}^{E S G}, t_{2.25}^{\prime}\right)$ & 0.140 & 0.109 \\
\hline & 4 & $\left(t_{1.785}^{f}, t_{3.121}^{\prime}\right)$ & 0.171 & 0.048 & $\left(t_{3.358}^{E S G}, t_{2.829}^{\prime}\right)$ & 0.594 & 0.246 \\
\hline & 5 & $\left(t_{1.531}^{f}, t_{1}^{\prime}\right)$ & 0.048 & 0.144 & $\left(t_{2.248}^{E S G}, t_{1.494}^{\prime}\right)$ & 0.210 & 0.352 \\
\hline & 6 & $\left(t_{2.258}^{f}, t_{1.83}^{\prime}\right)$ & 0.129 & 0.153 & $\left(t_{2.775}^{E S G}, t_{1.103}^{\prime}\right)$ & 0.191 & 0.503 \\
\hline & 7 & $\left(t_{3.445}^{f}, t_{2.858}^{\prime}\right)$ & 0.308 & 0.123 & $\left(t_{1.36}^{E S G}, t_{1.306}^{\prime}\right)$ & 0.111 & 0.229 \\
\hline & 8 & $\left(t_{1.758}^{f}, t_{2.89}^{\prime}\right)$ & 0.159 & 0.061 & $\left(t_{1.36}^{E S G}, t_{3.449}^{\prime}\right)$ & 0.293 & 0.047 \\
\hline & 9 & $\left(t_{4.5}^{f}, t_{3.516}^{\prime}\right)^{\prime}$ & 0.494 & 0.068 & $\left(t_{0.694}^{E S G}, t_{1}^{\prime}\right)$ & 0.043 & 0.130 \\
\hline$P^{f}=(0.25,0.25,0.25,0.25)$ & 10 & $\left(t_{1.758}^{f}, t_{1.604}^{\prime}\right)$ & 0.088 & 0.132 & $\left(t_{1.36}^{E S G}, t_{1.306}^{\prime}\right)$ & 0.111 & 0.229 \\
\hline \multirow[t]{10}{*}{$P^{E S G}=(0.33,0.33,0.33)$} & 11 & $\left(t_{2.82}^{f}, t_{1.28}^{\prime}\right)$ & 0.113 & 0.240 & $\left(t_{1.36}^{E S G}, t_{0.735}^{\prime}\right)$ & 0.062 & 0.278 \\
\hline & 12 & $\left(t_{1.531}^{f}, t_{0.93}^{\prime}\right)$ & 0.044 & 0.147 & $\left(t_{3.358}^{E S G}, t_{1.86}^{\prime}\right)$ & 0.390 & 0.449 \\
\hline & 13 & $\left(t_{2.531}^{f}, t_{1.929}^{\prime}\right)$ & 0.153 & 0.164 & $\left(t_{1.36}^{E S G}, t_{0.862}^{\prime}\right)$ & 0.073 & 0.267 \\
\hline & 14 & $\left(t_{2.82}^{f}, t_{3.109}^{\prime}\right)$ & 0.274 & 0.079 & $\left(t_{2.775}^{E S G}, t_{1.21}^{\prime}\right)$ & 0.210 & 0.484 \\
\hline & 15 & $\left(t_{1.758}^{f}, t_{2.054}^{\prime}\right)$ & 0.113 & 0.107 & $\left(t_{1.776}^{E S G}, t_{1.266}^{\prime}\right)$ & 0.140 & 0.304 \\
\hline & 16 & $\left(t_{2.82}^{f}, t_{3.109}^{\prime}\right)^{\prime}$ & 0.274 & 0.079 & $\left(t_{3.358}^{E S G}, t_{2.388}^{\prime}\right)$ & 0.501 & 0.338 \\
\hline & 17 & $\left(t_{3.445}^{f}, t_{2.621}^{\prime}\right)$ & 0.282 & 0.148 & $\left(t_{2.248}^{E S G}, t_{0.694}^{\prime}\right)$ & 0.098 & 0.464 \\
\hline & 18 & $\left(t_{1.531}^{f}, t_{1.563}^{\prime}\right)$ & 0.075 & 0.117 & $\left(t_{0.444}^{E S G}, t_{1.266}^{\prime}\right)$ & 0.035 & 0.076 \\
\hline & 19 & $\left(t_{2.531}^{f}, t_{1.778}^{\prime}\right)$ & 0.141 & 0.176 & $\left(t_{1.776}^{E S G}, t_{1}^{\prime}\right)$ & 0.111 & 0.333 \\
\hline & 20 & $\left(t_{1.32}^{f}, t_{2.136}^{\prime}\right)$ & 0.088 & 0.077 & $\left(t_{2.775}^{E S G}, t_{1.823}^{\prime}\right)$ & 0.316 & 0.378 \\
\hline
\end{tabular}

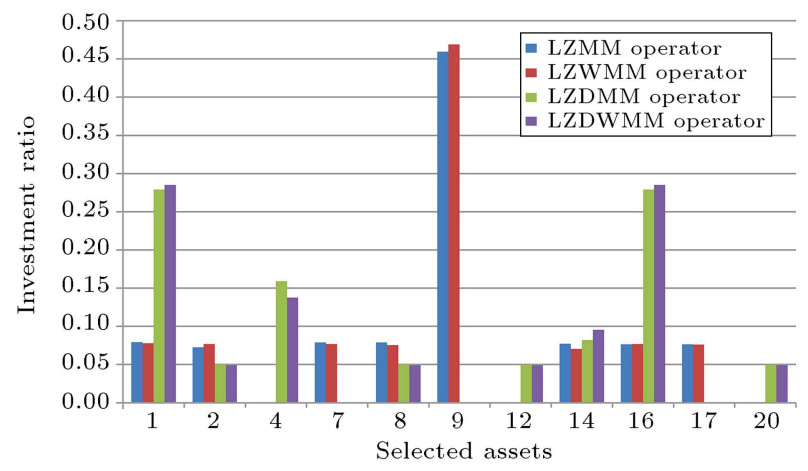

Figure 2. The selected assets and their investment ratio based on Model 1.

of the advantage of our proposed aggregation operators. In addition, more diversified portfolios can be constructed by changing the $\gamma$-value in Model 1 according to the investor's preferences.

\section{- Asset allocation using Model 2}

In this case, $f^{*}\left(x_{i}\right)=L S F 1, g^{*}\left(x_{i}\right)=L S F 1, P^{f}=$ $(0.25,0.25,0.25,0.25), \quad P^{E S G}=(0.33,0.33,0.33)$,

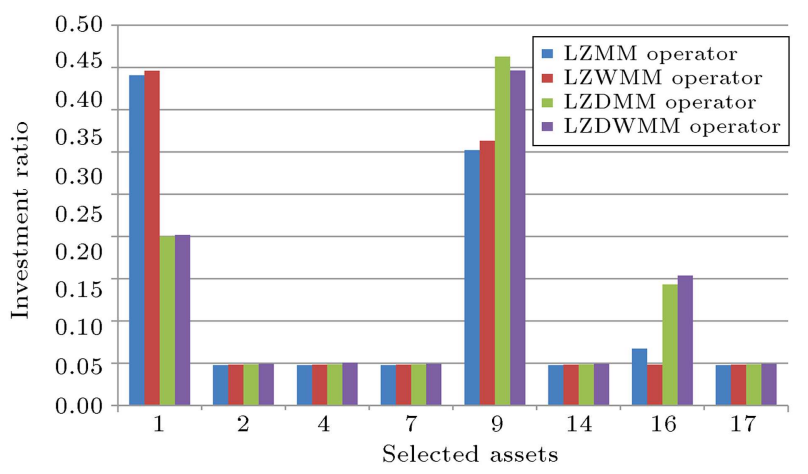

Figure 3. The selected assets and their investment ratio (Pareto solution 1) based on Model 2.

$w^{f}(0.3,0.3,0.25,0.15)$, and $w^{E S G}(0.4,0.3,0.3)$ are used to construct Model 2 based on the four proposed aggregation operators. Table 13 lists the selected portfolios. Figure 3 indicates that assets 1 and 9 outperform others when using LZMM and LZWMM operators. In addition, more budget is allocated to assets 1,9 , and 16 when using LZDMM 
Table 11. The aggregated values and their corresponding score and accuracy values resulting from LZDWMM operator for $f^{*}\left(x_{i}\right)=L S F 1, g^{*}\left(x_{i}\right)=L S F 1, w^{f}=(0.3,0.3,0.25,0.15)$, and $w^{E S G}=(0.4,0.3,0.3)$.

\begin{tabular}{|c|c|c|c|c|c|c|c|}
\hline \multirow[b]{2}{*}{$\begin{array}{c}\text { Parameter } \\
\text { vector }\end{array}$} & \multirow[b]{2}{*}{$\begin{array}{l}\text { Asset } \\
\text { ID }\end{array}$} & \multicolumn{3}{|c|}{ Financial criteria } & \multicolumn{3}{|c|}{ ESG criteria } \\
\hline & & $\begin{array}{c}\text { Aggregated } \\
\text { value }\end{array}$ & $\begin{array}{l}\text { Score } \\
\text { value }\end{array}$ & $\begin{array}{c}\text { Accuracy } \\
\text { value }\end{array}$ & $\begin{array}{c}\text { Aggregated } \\
\text { value }\end{array}$ & $\begin{array}{l}\text { Score } \\
\text { value }\end{array}$ & $\begin{array}{c}\text { Accuracy } \\
\text { value }\end{array}$ \\
\hline & 1 & $\left(t_{3.204}^{f}, t_{3.02}^{\prime}\right)$ & 0.302 & 0.098 & $\left(t_{3.411}^{E S G}, t_{2.344}^{\prime}\right)$ & 0.500 & 0.353 \\
\hline & 2 & $\left(t_{3.134}^{f}, t_{2.387}^{\prime}\right)$ & 0.234 & 0.158 & $\left(t_{2.731}^{E S G}, t_{1.453}^{\prime}\right)$ & 0.248 & 0.435 \\
\hline & 3 & $\left(t_{2.836}^{f}, t_{1.196}^{\prime}\right)$ & 0.106 & 0.248 & $\left(t_{0.991}^{E S G}, t_{2.27}^{\prime}\right)$ & 0.141 & 0.107 \\
\hline & 4 & $\left(t_{1.862}^{f}, t_{3.158}^{\prime}\right)$ & 0.184 & 0.049 & $\left(t_{3.411}^{E S G}, t_{2.763}^{\prime}\right)$ & 0.589 & 0.264 \\
\hline & 5 & $\left(t_{1.566}^{f}, t_{1.194}^{\prime}\right)$ & 0.058 & 0.137 & $\left(t_{2.163}^{E S G}, t_{1.552}^{\prime}\right)$ & 0.210 & 0.331 \\
\hline & 6 & $\left(t_{2.341}^{f}, t_{1.905}^{\prime}\right)$ & 0.139 & 0.153 & $\left(t_{2.731}^{E S G}, t_{1.102}^{\prime}\right)$ & 0.188 & 0.495 \\
\hline & 7 & $\left(t_{3.478}^{f}, t_{2.925}^{\prime}\right)$ & 0.318 & 0.117 & $\left(t_{1.386}^{E S G}, t_{1.325}^{\prime}\right)$ & 0.115 & 0.232 \\
\hline & 8 & $\left(t_{1.85}^{f}, t_{2.908}^{\prime}\right)^{\prime}$ & 0.168 & 0.063 & $\left(t_{1.476}^{E S G}, t_{3.482}^{\prime}\right)$ & 0.321 & 0.048 \\
\hline & 9 & $\left(t_{4.449}^{f}, t_{3.465}^{\prime}\right)$ & 0.482 & 0.074 & $\left(t_{0.706}^{E S G}, t_{1}^{\prime}\right)$ & 0.044 & 0.132 \\
\hline$P^{f}=(0.25,0.25,0.25,0.25)$ & 10 & $\left(t_{1.819}^{f}, t_{1.691}^{\prime}\right)$ & 0.096 & 0.131 & $\left(t_{1.334}^{E S G}, t_{1.35}^{\prime}\right)$ & 0.113 & 0.221 \\
\hline \multirow[t]{10}{*}{$P^{E S G}=(0.33,0.33,0.33)$} & 11 & $\left(t_{2.764}^{f}, t_{1.442}^{\prime}\right)$ & 0.124 & 0.220 & $\left(t_{1.407}^{E S G}, t_{0.709}^{\prime}\right)$ & 0.062 & 0.289 \\
\hline & 12 & $\left(t_{1.566}^{f}, t_{1.145}^{\prime}\right)$ & 0.056 & 0.140 & $\left(t_{3.256}^{E S G}, t_{1.871}^{\prime}\right)$ & 0.381 & 0.433 \\
\hline & 13 & $\left(t_{2.602}^{f}, t_{1.957}^{\prime}\right)$ & 0.159 & 0.166 & $\left(t_{1.349}^{E S G}, t_{0.896}^{\prime}\right)$ & 0.076 & 0.262 \\
\hline & 14 & $\left(t_{2.874}^{f}, t_{3.219}^{\prime}\right)$ & 0.289 & 0.070 & $\left(t_{2.873}^{E S G}, t_{1.288}^{\prime}\right)$ & 0.231 & 0.487 \\
\hline & 15 & $\left(t_{1.889}^{f}, t_{2.116}^{\prime}\right)$ & 0.125 & 0.111 & $\left(t_{1.739}^{E S G}, t_{1.294}^{\prime}\right)$ & 0.141 & 0.294 \\
\hline & 16 & $\left(t_{2.915}^{f}, t_{3.231}^{\prime}\right)$ & 0.294 & 0.070 & $\left(t_{3.406}^{f}, t_{2.567}^{\prime}\right)$ & 0.500 & 0.353 \\
\hline & 17 & $\left(t_{3.406}^{f}, t_{2.567}^{\prime}\right)$ & 0.273 & 0.153 & $\left(t_{2.251}^{E S G}, t_{0.714}^{\prime}\right)$ & 0.101 & 0.462 \\
\hline & 18 & $\left(t_{1.601}^{f}, t_{1.664}^{\prime}\right)$ & 20.083 & 0.117 & $\left(t_{0.455}^{E S G}, t_{1.246}^{\prime}\right)$ & 0.035 & 0.078 \\
\hline & 19 & $\left(t_{2.535}^{f}, t_{1.804}^{\prime}\right)$ & 0.143 & 0.174 & $\left(t_{1.804}^{E S G}, t_{1.005}^{\prime}\right)$ & 0.113 & 0.338 \\
\hline & 20 & $\left(t_{1.447}^{f}, t_{2.14}^{\prime}\right)^{\prime}$ & 0.097 & 0.084 & $\left(t_{2.731}^{E S G}, t_{1.851}^{\prime}\right)$ & 0.316 & 0.367 \\
\hline
\end{tabular}

and LZDWMM operators. All of these assets are allocated to the optimal portfolios based on a tradeoff between the financial and the ethical goals considering the expert's reliability under the proposed aggregation operators. Moreover, the chosen assets in Model 2 based on these operators are the same; however, their corresponding investment ratios are slightly different. This feature highlights an advantage of our proposed aggregation operators. The result reported in Table 13 is only one of the Pareto solutions obtained from NSGA-II. As observed, the financial goals of the portfolios listed in Table 13 are greater than the ethical goals in all situations. Now, if the investor prefers to choose the portfolios with higher ethical performance, he/she should consider the assets listed in Table 14. According to Figure 4, more capital is devoted to assets 1,4 , and 16 in all the proposed aggregation operators. Moreover, some assets such as 5, 8, 12, and 20 selected in Table 14 have higher ESG score values than those of the other assets such as 7, 9, 14, and 17 chosen

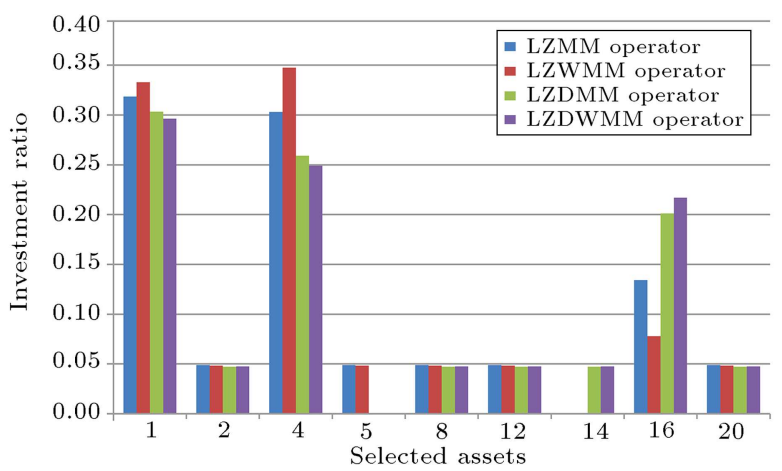

Figure 4. The selected assets and their investment ratio (Pareto solution 2) based on Model 2.

in Table 13. On the contrary, assets 7, 9, 14, and 17 chosen in Table 13 have higher financial score values than those of assets $5,8,12$, and 20 selected in Table 14. Therefore, it can be concluded that Model 2 can generate far more diversified portfolios based on the investor's preferences and examine the trade-off among the financial and ethical goals. 
Table 12. The selected assets and their investment ratio in the portfolio by Model 1.

\begin{tabular}{cccccccccccc}
\hline Operator & Financial goal & \multicolumn{7}{c}{ Selected assets and their investment ratio } \\
\hline LZMM & \multirow{2}{*}{1.153} & ID & 1 & 2 & 7 & 8 & 9 & 14 & 16 & 17 \\
& & Portions & 0.079 & 0.073 & 0.079 & 0.079 & 0.460 & 0.077 & 0.077 & 0.077 \\
LZWMM & \multirow{2}{*}{1.114} & ID & 1 & 2 & 7 & 8 & 9 & 14 & 16 & 17 \\
& & Portions & 0.078 & 0.077 & 0.077 & 0.076 & 0.469 & 0.070 & 0.077 & 0.076 \\
LZDMM & \multirow{2}{*}{0.2358} & ID & 1 & 2 & 4 & 8 & 12 & 14 & 16 & 20 \\
& & & Portions & 0.279 & 0.050 & 0.159 & 0.050 & 0.050 & 0.082 & 0.279 & 0.050 \\
LZDWMM & \multirow{2}{*}{0.2503} & ID & 1 & 2 & 4 & 8 & 12 & 14 & 16 & 20 \\
& & & Portions & 0.285 & 0.049 & 0.138 & 0.049 & 0.049 & 0.096 & 0.285 & 0.049 \\
\hline
\end{tabular}

Table 13. The selected assets and their investment ratio (Pareto solution 1) in the portfolio using Model 2.

\begin{tabular}{|c|c|c|c|c|c|c|c|c|c|c|c|}
\hline \multirow{2}{*}{$\frac{\text { Operator }}{\text { LZMM }}$} & \multirow{2}{*}{$\begin{array}{c}\begin{array}{c}\text { Financial } \\
\text { goal }\end{array} \\
1.123\end{array}$} & \multirow{2}{*}{$\begin{array}{c}\begin{array}{c}\text { Ethical } \\
\text { goal }\end{array} \\
0.925\end{array}$} & \multicolumn{9}{|c|}{ Selected assets and their investment ratio } \\
\hline & & & ID & 1 & 2 & 4 & 7 & 9 & 14 & 16 & 17 \\
\hline & & & Portions & 0.391 & 0.048 & 0.048 & 0.048 & 0.302 & 0.048 & 0.067 & 0.048 \\
\hline \multirow[t]{2}{*}{ LZWMM } & 1.087 & 0.905 & ID & 1 & 2 & 4 & 7 & 9 & 14 & 16 & 17 \\
\hline & & & Portions & 0.396 & 0.048 & 0.048 & 0.048 & 0.313 & 0.048 & 0.048 & 0.048 \\
\hline \multirow[t]{2}{*}{ LZDMM } & 0.364 & 0.249 & ID & 1 & 2 & 4 & 7 & 9 & 14 & 16 & 17 \\
\hline & & & Portions & 0.200 & 0.049 & 0.049 & 0.049 & 0.413 & 0.049 & 0.143 & 0.049 \\
\hline \multirow[t]{2}{*}{ LZDWMM } & 0.361 & 0.259 & ID & 1 & 2 & 4 & 7 & 9 & 14 & 16 & 17 \\
\hline & & & Portions & 0.202 & 0.049 & 0.051 & 0.049 & 0.397 & 0.049 & 0.154 & 0.049 \\
\hline
\end{tabular}

Table 14. The selected assets and their investment ratio (Pareto solution 2) in the portfolio using Model 2.

\begin{tabular}{cccccccccccccc}
\hline Operator & $\begin{array}{c}\text { Financial } \\
\text { goal }\end{array}$ & $\begin{array}{c}\text { Ethical } \\
\text { goal }\end{array}$ & \multicolumn{10}{c}{ Selected assets and their investment ratio } \\
\hline LZMM & 0.834 & 1.294 & ID & 1 & 2 & 4 & 5 & 8 & 12 & 16 & 20 \\
& & & Portions & 0.319 & 0.049 & 0.303 & 0.049 & 0.049 & 0.049 & 0.134 & 0.049 \\
LZWMM & 0.796 & 1.129 & ID & 1 & 2 & 4 & 5 & 8 & 12 & 16 & 20 \\
& & & & Portions & 0.333 & 0.048 & 0.347 & 0.048 & 0.048 & 0.048 & 0.078 & 0.048 \\
LZDMM & 0.227 & 0.471 & ID & 1 & 2 & 4 & 8 & 12 & 14 & 16 & 20 \\
& & & & Portions & 0.303 & 0.047 & 0.259 & 0.047 & 0.047 & 0.047 & 0.201 & 0.047 \\
LZDWMM & 0.239 & 0.474 & ID & 1 & 2 & 4 & 8 & 12 & 14 & 16 & 20 \\
& & & & Portions & 0.296 & 0.048 & 0.249 & 0.048 & 0.048 & 0.048 & 0.217 & 0.048 \\
\hline
\end{tabular}

\section{- Asset allocation using Model 3}

In this case, $\delta=0.2$ and $\varphi=0.4$ are employed to establish Model 3 based on the four proposed aggregation operators. The selected portfolios are listed in Table 15. According to Figure 5, assets 1 and 9 outperform the others when using LZMM operator and LZWMM operator to fuse the evaluation information. In addition, more budget is devoted to assets 2, 3, and 11 when using LZDMM and LZDWMM operators to aggregate the evaluation information. Moreover, financial score and ESG score values of the selected assets $(1,2,3,9$, and
11) are high, and their financial accuracy and ESG accuracy values are within the admissible bounds.

In case the diversification of the selected portfolios does not satisfy the investor, more portfolios are constructed by changing the predefined $\delta$ - and $\varphi$-values in Model 3.

\subsection{Discussion and sensitivity analysis}

The main feature of portfolio optimization problems emphasizes the trade-off between two conflicting goals. In the traditional portfolio theory, conflict is observed between the return and risk. However, the conflict in 
Table 15. The selected assets and their investment ratio in the portfolio using Model 3.

\begin{tabular}{|c|c|c|c|c|c|c|c|c|c|c|c|}
\hline \multirow{2}{*}{$\begin{array}{c}\text { Operator } \\
\text { LZMM }\end{array}$} & \multirow{2}{*}{$\begin{array}{c}\begin{array}{c}\text { Financial } \\
\text { goal }\end{array} \\
1.059\end{array}$} & \multirow{2}{*}{$\begin{array}{c}\begin{array}{c}\text { Ethical } \\
\text { goal }\end{array} \\
0.962\end{array}$} & \multicolumn{9}{|c|}{ Selected assets and their investment ratio } \\
\hline & & & ID & 1 & 2 & 3 & 7 & 9 & 14 & 16 & 17 \\
\hline & & & Portions & 0.396 & 0.066 & 0.064 & 0.067 & 0.229 & 0.058 & 0.055 & 0.066 \\
\hline \multirow[t]{2}{*}{ LZWMM } & 1.012 & 0.911 & ID & 1 & 2 & 3 & 7 & 9 & 14 & 16 & 17 \\
\hline & & & Portions & 0.375 & 0.089 & 0.071 & 0.074 & 0.170 & 0.070 & 0.076 & 0.075 \\
\hline \multirow[t]{2}{*}{ LZDMM } & 0.1403 & 0.1403 & ID & 2 & 3 & 6 & 11 & 12 & 13 & 17 & 19 \\
\hline & & & Portions & 0.155 & 0.276 & 0.089 & 0.179 & 0.069 & 0.073 & 0.079 & 0.080 \\
\hline \multirow[t]{2}{*}{ LZDWMM } & 0.1435 & 0.045 & ID & 2 & 3 & 6 & 11 & 12 & 13 & 17 & 19 \\
\hline & & & Portions & 0.103 & 0.237 & 0.076 & 0.345 & 0.055 & 0.050 & 0.083 & 0.051 \\
\hline
\end{tabular}

Table 16. Ranking orders for different parameter vectors $P$ based on LZMM operator (financial criteria).

\begin{tabular}{cl}
\hline $\boldsymbol{P}$ vector & Ranking \\
\hline$P^{f}=(1,0,0,0)$ & $x_{9}>x_{7}>x_{1}>x_{17}>x_{14}>x_{16}>x_{2}>x_{4}>x_{8}>x_{13}>x_{19}>x_{6}>x_{11}>x_{15}>x_{3}>x_{10}>x_{20}>x_{18}>x_{5}>x_{12}$ \\
$P^{f}=(2,0,0,0)$ & $x_{9}>x_{7}>x_{16}>x_{1}>x_{17}>x_{14}>x_{2}>x_{4}>x_{15}>x_{19}>x_{13}>x_{8}>x_{11}>x_{6}>x_{20}>x_{10}>x_{3}>x_{18}>x_{5}>x_{12}$ \\
$P^{f}=(1,1,0,0)$ & $x_{9}>x_{7}>x_{1}>x_{17}>x_{14}>x_{16}>x_{2}>x_{8}>x_{4}>x_{13}>x_{19}>x_{6}>x_{11}>x_{15}>x_{3}>x_{20}>x_{10}>x_{18}>x_{5}>x_{12}$ \\
$P^{f}=(1,1,1,0)$ & $x_{9}>x_{7}>x_{1}>x_{17}>x_{14}>x_{16}>x_{2}>x_{8}>x_{4}>x_{13}>x_{19}>x_{6}>x_{11}>x_{15}>x_{3}>x_{10}>x_{20}>x_{18}>x_{5}>x_{12}$ \\
$P^{f}=(1,1,1,1)$ & $x_{9}>x_{7}>x_{1}>x_{17}>x_{14}>x_{16}>x_{2}>x_{8}>x_{13}>x_{4}>x_{6}>x_{19}>x_{11}>x_{15}>x_{3}>x_{10}>x_{20}>x_{18}>x_{5}>x_{12}$
\end{tabular}

Table 17. Ranking orders for different parameter vectors $P$ based on LZDMM operator (financial criteria).

\begin{tabular}{cl}
\hline $\boldsymbol{P}$ vector & Ranking \\
\hline$P^{f}=(1,0,0,0)$ & $x_{9}>x_{7}>x_{1}>x_{17}>x_{14}>x_{16}>x_{2}>x_{8}>x_{13}>x_{4}>x_{6}>x_{19}>x_{11}>x_{15}>x_{3}>x_{10}>x_{20}>x_{18}>x_{5}>x_{12}$ \\
$P^{f}=(2,0,0,0)$ & $x_{9}>x_{7}>x_{1}>x_{17}>x_{14}>x_{16}>x_{2}>x_{8}>x_{13}>x_{4}>x_{6}>x_{19}>x_{11}>x_{15}>x_{3}>x_{10}>x_{20}>x_{18}>x_{5}>x_{12}$ \\
$P^{f}=(1,1,0,0)$ & $x_{9}>x_{7}>x_{1}>x_{17}>x_{14}>x_{16}>x_{2}>x_{8}>x_{4}>x_{13}>x_{19}>x_{6}>x_{11}>x_{15}>x_{3}>x_{10}>x_{20}>x_{18}>x_{5}>x_{12}$ \\
$P^{f}=(1,1,1,0)$ & $x_{9}>x_{7}>x_{1}>x_{17}>x_{14}>x_{16}>x_{2}>x_{4}>x_{8}>x_{13}>x_{19}>x_{6}>x_{11}>x_{15}>x_{3}>x_{10}>x_{20}>x_{18}>x_{5}>x_{12}$ \\
$P^{f}=(1,1,1,1)$ & $x_{9}>x_{7}>x_{1}>x_{17}>x_{14}>x_{16}>x_{2}>x_{4}>x_{8}>x_{13}>x_{19}>x_{6}>x_{11}>x_{15}>x_{3}>x_{10}>x_{20}>x_{18}>x_{5}>x_{12}$ \\
\hline
\end{tabular}

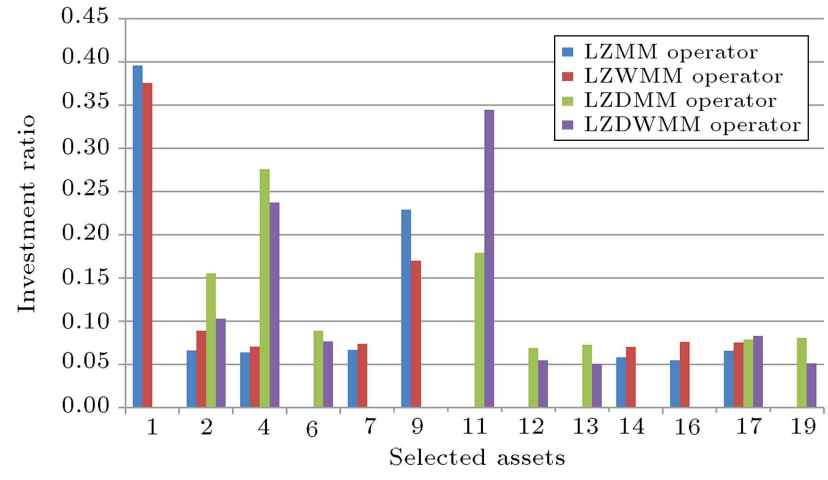

Figure 5. The selected assets and their investment ratio based on Model 3.

this study is between the financial and ESG goals as well as the score values and accuracy values. These trade-offs are adequately considered in all three proposed models to generate more diversified portfolios. In the following, the impact of critical parameters on the proposed qualitative portfolio models is analyzed.

\subsubsection{The influence of parameter vector $P$ on the asset allocation by Model 1}

In this subsection, different parameters of vector are used to fuse the evaluation information and analyze the ranking orders in terms of only financial criteria based on LZMM and LZDMM operators. Tables 16 and 17 present the results obtained from LZMM and LZDMM operators, respectively. Obviously, the ranking orders in the LZMM and LZDMM operators are slightly different. This difference is indicative of an advantage of our proposed aggregation operators. In addition, the larger the values for parameter vector $P$, the lower the score values in LZMM operator; on the contrary, the greater the values of parameter vector $P$, the larger the score values in LZDMM operator. Consequently, parameter vector indicates the idea of decision-makers or investors. Different parameters of vector $P$ are used for further analysis and establishment of Model 1 based on the LZMM and LZDMM operator for $\gamma=0.3$. Table 18 shows the financial and ESG goals for different 
Table 18. Financial and ESG goals corresponding to different parameter vectors $P$ in Model 1 for $\gamma=0.3$.

\begin{tabular}{|c|c|c|c|}
\hline Operator & Parameter vector & Financial goal & ESG level \\
\hline \multirow{10}{*}{ 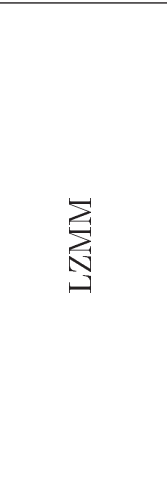 } & $\mathrm{C} 1: P^{f}=(1,0,0,0)$ & 1.206 & 0.694 \\
\hline & $P^{E S G}=(1,0,0)$ & & \\
\hline & $\mathrm{C} 2: P^{f}=(2,0,0,0)$ & 0.8844 & 0.543 \\
\hline & $P^{E S G}=(2,0,0)$ & & \\
\hline & $\mathrm{C} 3: P^{f}=(1,1,0,0)$ & 0.8324 & 0.526 \\
\hline & $P^{E S G}=(1,1,0)$ & & \\
\hline & $\mathrm{C} 4: P^{f}=(1,1,1,0)$ & 0.7447 & 0.4786 \\
\hline & $P^{E S G}=(1,1,0)$ & & \\
\hline & $\mathrm{C} 5: P^{f}=(1,1,1,1)$ & 0.6817 & 0.421 \\
\hline & $P^{E S G}=(1,1,1)$ & & \\
\hline \multirow{10}{*}{ 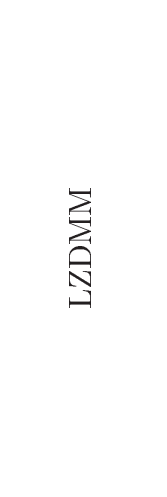 } & $\mathrm{C} 1: P^{f}=(1,0,0,0)$ & 0.281 & 0.3 \\
\hline & $P^{E S G}=(1,0,0)$ & & \\
\hline & $\mathrm{C} 2: P^{f}=(2,0,0,0)$ & 0.6571 & 0.36 \\
\hline & $P^{E S G}=(2,0,0)$ & & \\
\hline & $\mathrm{C} 3: P^{f}=(1,1,0,0)$ & 0.7166 & 0.375 \\
\hline & $P^{E S G}=(1,1,0)$ & & \\
\hline & $\mathrm{C} 4: P^{f}=(1,1,1,0)$ & 1.096 & 0.393 \\
\hline & $P^{E S G}=(1,1,0)$ & & \\
\hline & $\mathrm{C} 5: P^{f}=(1,1,1,1)$ & 1.483 & 0.577 \\
\hline & $P^{E S G}=(1,1,1)$ & & \\
\hline
\end{tabular}

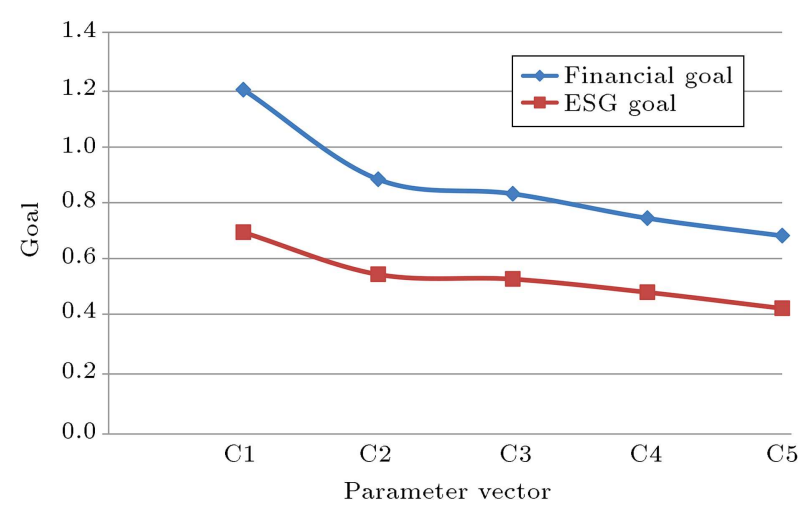

Figure 6. The effect of different parameter vectors in Model 1 based on LZMM operator for $\gamma=0.3$.

values of $P$. As shown in Figure 6, both financial and ESG performances of portfolios obtained based on LZMM operator are weakened with larger values of vector $P$. On the contrary, according to Figure 7 , both financial and ESG performance of portfolios obtained based on LZDMM operator are enhanced with larger values of vector $P$. Therefore, if an investor is a riskseeker, the parameter vector can generally be set as either $P=(1,0, \ldots, 0)$ in the LZMM operator or as $P=(0,0, \ldots, 1)$ in the LZDMM operator. On the contrary, if an investor is a risk-averter, the parameter vector can generally be set as either $P=(0,0, \ldots, 1)$

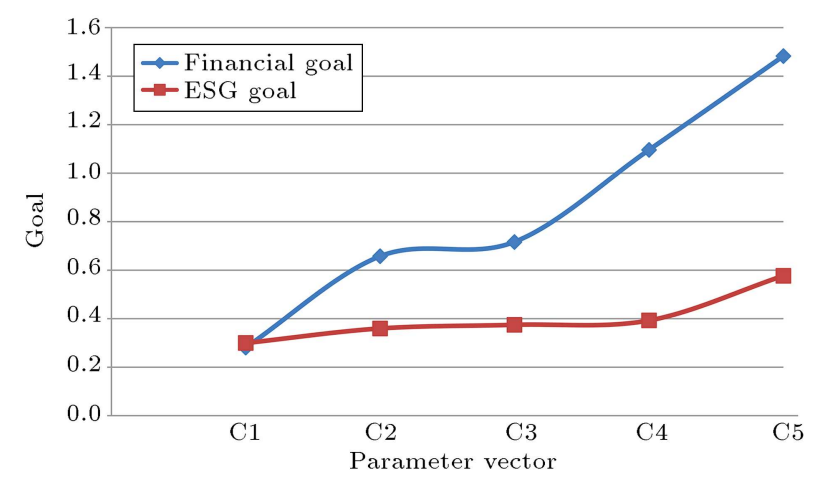

Figure 7. The effect of different parameter vectors in Model 1 based on LZDMM operator for $\gamma=0.3$.

in the LZMM operator or as $P=(1,0, \ldots, 0)$ in the LZDMM operator. Finally, in the case of a neutral investor, the parameter vector can generally be set as $P=\left(\frac{1}{n}, \frac{1}{n}, \ldots, \frac{1}{n}\right)$. Consequently, every investor can set the value of vector $P$ according to his/her preferences.

\subsubsection{The influence of desirable ESG level $\gamma$ on the asset allocation by Model 1}

To investigate the role of Desirable Ethical (ESG) level $\gamma$ on the asset allocation through Model 1 , different $\gamma$ values are used to analyze the results that are given in Table 19 . 
Table 19. Asset allocation to different predefined ESG levels in Model 1.

\begin{tabular}{|c|c|c|c|c|c|c|c|c|c|c|}
\hline Operator & $\gamma$ & Financial goal & & Select & d asse & and $t$ & neir in & estmel & t ratio & \\
\hline \multirow{11}{*}{ 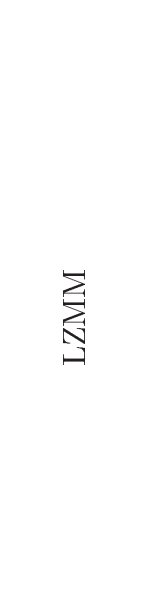 } & 0.1 & 1.156 & 1 & 2 & 7 & 8 & 9 & 14 & 16 & 17 \\
\hline & & & 0.076 & 0.074 & 0.076 & 0.076 & 0.469 & 0.076 & 0.076 & 0.077 \\
\hline & 0.5 & 1.142 & 1 & 2 & 7 & 8 & 9 & 14 & 16 & 17 \\
\hline & & & 0.081 & 0.081 & 0.081 & 0.081 & 0.432 & 0.082 & 0.082 & 0.081 \\
\hline & 0.7 & 1.137 & 1 & 2 & 7 & 8 & 9 & 14 & 16 & 17 \\
\hline & & & 0.099 & 0.079 & 0.084 & 0.081 & 0.416 & 0.075 & 0.092 & 0.075 \\
\hline & 0.9 & 1.112 & 1 & 2 & 4 & 7 & 9 & 14 & 16 & 17 \\
\hline & & & 0.315 & 0.055 & 0.064 & 0.062 & 0.299 & 0.058 & 0.086 & 0.062 \\
\hline & 1.25 & 0.887 & 1 & 2 & 4 & 8 & 12 & 14 & 16 & 20 \\
\hline & & & 0.271 & 0.055 & 0.190 & 0.050 & 0.050 & 0.065 & 0.271 & 0.050 \\
\hline & $\geq 1.5$ & Infeasible & & & & & & & & \\
\hline \multirow{11}{*}{ 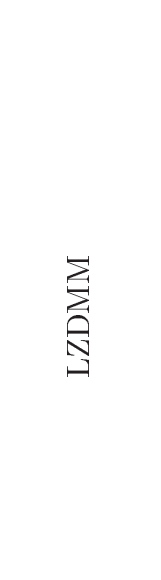 } & 0.1 & 0.367 & 1 & 2 & 4 & 7 & 9 & 14 & 16 & 17 \\
\hline & & & 0.078 & 0.077 & 0.078 & 0.078 & 0.454 & 0.075 & 0.079 & 0.081 \\
\hline & 0.2 & 0.365 & 1 & 2 & 4 & 7 & 9 & 14 & 16 & 17 \\
\hline & & & 0.085 & 0.076 & 0.083 & 0.070 & 0.455 & 0.075 & 0.085 & 0.071 \\
\hline & 0.3 & 0.323 & 1 & 2 & 4 & 7 & 9 & 14 & 16 & 17 \\
\hline & & & 0.230 & 0.067 & 0.129 & 0.069 & 0.259 & 0.068 & 0.111 & 0.067 \\
\hline & 0.4 & 0.271 & 1 & 2 & 4 & 7 & 8 & 14 & 16 & 17 \\
\hline & & & 0.313 & 0.053 & 0.052 & 0.079 & 0.051 & 0.080 & 0.313 & 0.059 \\
\hline & 0.45 & 0.2387 & 1 & 2 & 4 & 8 & 12 & 14 & 16 & 20 \\
\hline & & & 0.297 & 0.051 & 0.132 & 0.051 & 0.050 & 0.071 & 0.297 & 0.050 \\
\hline & $\geq 1.5$ & Infeasible & & & & & & & & \\
\hline
\end{tabular}

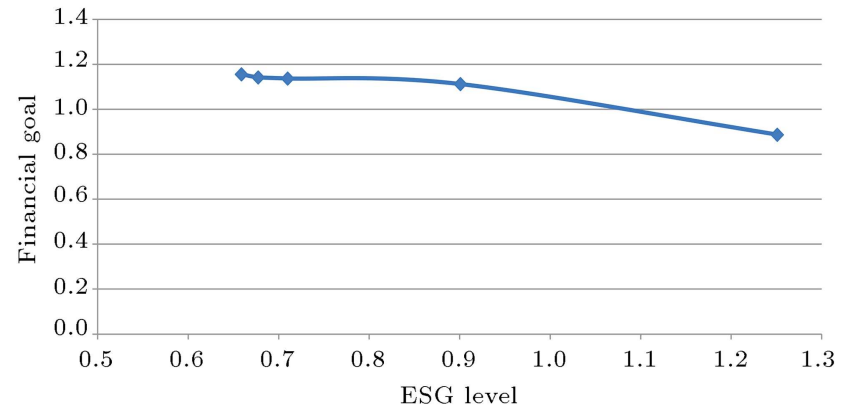

Figure 8. Trade-off among the financial goal and ESG level using Model 1 based on LZMM operator.

In this subsection, sensitivity analysis is carried out by changing the desirable ESG level of the portfolio $\gamma$. According to Figures 8 and 9, upon increasing the $\gamma$ value, the attainment level of the financial goal becomes lower in Model 1 established based on both LZMM and LZDMM operators. This is in line with the trade-off among the financial and ESG goals of the portfolio. In addition, Model 1 selects the assets with better ESG performance resulting from an increase in the desirable

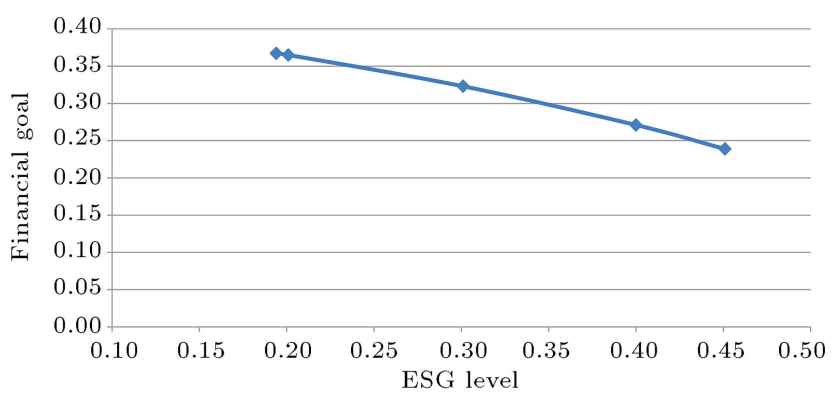

Figure 9. Trade-off between the financial goal and ESG level using Model 1 based on LZDMM operator.

ESG level of the portfolio $\gamma$. For example, asset 9 that exhibits high financial performance is not chosen when increasing the $\gamma$-value due to its low ethical performance. Moreover, the cardinality constraint as well as the minimum and maximum fraction of investment in each asset $\left(l_{i}\right.$ and $\left.u_{i}\right)$ are employed to construct more diversified portfolios. In other words, more diversified portfolios can be constructed by changing the maximum and minimum fraction $\left(l_{i}\right.$ and $u_{i}$ ) in Model 1 based on the investor's preferences. 
Table 20. Asset allocation using Model 3 based on the LZMM operator.

\begin{tabular}{|c|c|c|c|c|c|c|c|c|c|c|c|}
\hline$\frac{\varphi}{0.1}$ & $\delta$ & Financial goal & ESG goal & \multicolumn{8}{|c|}{ Selected assets and investment ratio } \\
\hline & & & & & & & & & & & \\
\hline & 0.1 & 1.128 & 0.911 & 1 & 2 & 4 & 7 & 9 & 14 & 16 & 17 \\
\hline & & & & 0.393 & 0.048 & 0.048 & 0.048 & 0.317 & 0.048 & 0.048 & 0.048 \\
\hline & 0.3 & 0.9446 & 0.702 & 1 & 2 & 3 & 7 & 9 & 11 & 14 & 17 \\
\hline & & & & 0.153 & 0.100 & 0.144 & 0.101 & 0.141 & 0.115 & 0.103 & 0.144 \\
\hline & 0.5 & 0.597 & 0.604 & 2 & 3 & 5 & 6 & 10 & 11 & 12 & 19 \\
\hline & & & & 0.050 & 0.382 & 0.050 & 0.063 & 0.055 & 0.094 & 0.252 & 0.054 \\
\hline \multicolumn{12}{|l|}{0.3} \\
\hline & 0.1 & 1.107 & 0.961 & 1 & 2 & 4 & 7 & 9 & 14 & 16 & 17 \\
\hline & & & & 0.397 & 0.049 & 0.049 & 0.049 & 0.260 & 0.049 & 0.097 & 0.049 \\
\hline & 0.3 & 0.927 & 0.796 & 1 & 2 & 3 & 6 & 9 & 11 & 16 & 17 \\
\hline & & & & 0.159 & 0.097 & 0.111 & 0.100 & 0.179 & 0.124 & 0.127 & 0.103 \\
\hline & 0.5 & 0.517 & 0.647 & 2 & 3 & 5 & 6 & 10 & 11 & 12 & 19 \\
\hline & & & & 0.050 & 0.310 & 0.052 & 0.050 & 0.050 & 0.102 & 0.338 & 0.050 \\
\hline \multicolumn{12}{|l|}{0.5} \\
\hline & 0.1 & 1.111 & 0.943 & 1 & 2 & 4 & 7 & 9 & 14 & 16 & 17 \\
\hline & & & & 0.398 & 0.050 & 0.057 & 0.052 & 0.275 & 0.052 & 0.065 & 0.050 \\
\hline & 0.3 & 0.939 & 0.69 & 1 & 2 & 3 & 7 & 9 & 11 & 14 & 17 \\
\hline & & & & 0.124 & 0.124 & 0.123 & 0.125 & 0.109 & 0.116 & 0.106 & 0.175 \\
\hline & 0.5 & 0.486 & 0.608 & 2 & 3 & 5 & 6 & 10 & 11 & 12 & 19 \\
\hline & & & & 0.058 & 0.346 & 0.062 & 0.057 & 0.057 & 0.102 & 0.259 & 0.059 \\
\hline \multicolumn{12}{|l|}{0.7} \\
\hline & 0.1 & 0.944 & 1.032 & 1 & 2 & 4 & 6 & 12 & 14 & 16 & 17 \\
\hline & & & & 0.196 & 0.092 & 0.081 & 0.090 & 0.070 & 0.152 & 0.188 & 0.130 \\
\hline & 0.3 & 0.938 & 0.608 & 2 & 3 & 6 & 7 & 9 & 11 & 14 & 17 \\
\hline & & & & 0.129 & 0.087 & 0.089 & 0.086 & 0.134 & 0.088 & 0.118 & 0.269 \\
\hline & 0.5 & 0.569 & 0.556 & 3 & 5 & 6 & 10 & 11 & 12 & 17 & 19 \\
\hline & & & & 0.131 & 0.066 & 0.069 & 0.058 & 0.480 & 0.070 & 0.062 & 0.064 \\
\hline
\end{tabular}

\subsubsection{The effect of admissible financial accuracy level $\delta$ and admissible ESG accuracy level $\varphi$ on the asset allocation by Model 3}

In this case, sensitivity analysis is conducted by changing the minimum admissible accuracy level of the financial goal $\delta$ as well as the minimum admissible accuracy level of ESG goal $\varphi$ in the portfolio. Table 20 reports the computational results according to which the attainment level of both financial and ESG goals decreases upon increasing the $\delta$ - and $\varphi$-values. This issue is in accordance with the trade-off between the score and accuracy values in the portfolio, as observed in Figures 10-12. As mentioned in Section 4, the relation between the score and accuracy values is similar to that between the mean and variance in statistics. Model 3 generates a comprehensive convergence between the financial score and financial accuracy values and ESG score and ESG accuracy value. Therefore, Model 3 is more suitable for risky socially responsible investors when they aim to obtain both the maximum financial and ethical goals along with a limited accuracy level. 


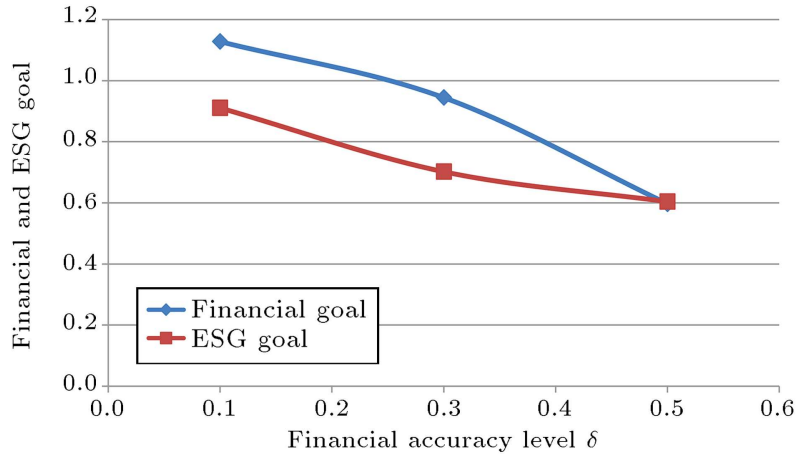

Figure 10. Trade-off between the financial and ESG goals and financial accuracy level using Model 3 with the ESG accuracy level of $\varphi=0.1$.

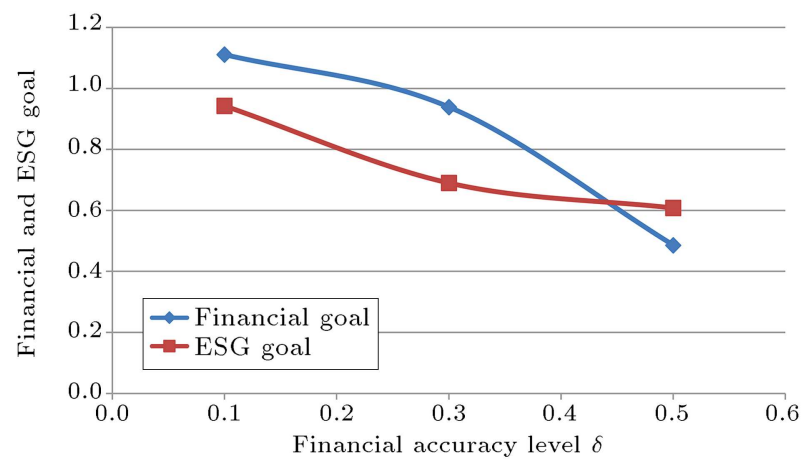

Figure 11. Trade-off between the financial and ESG goals and financial accuracy level using Model 3 with the ESG accuracy level of $\varphi=0.5$.

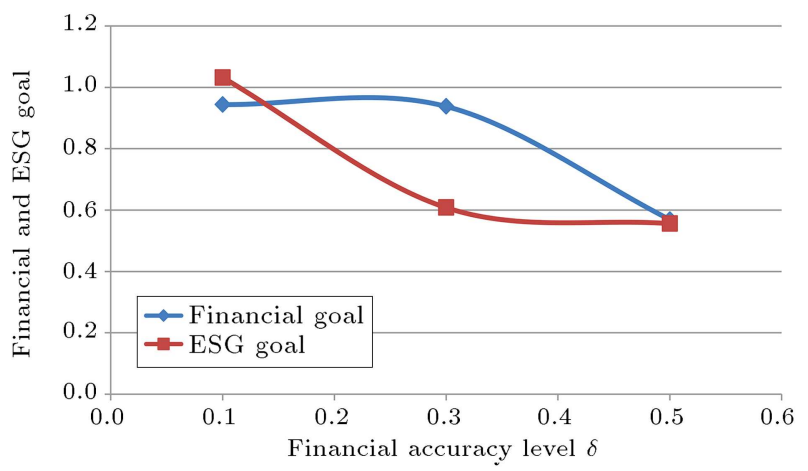

Figure 12. Trade-off between financial goal and ESG goal and financial accuracy level using Model 3 with the ESG accuracy level of $\varphi=0.7$.

\subsection{Managerial results}

As discussed earlier, the proposed qualitative framework includes application of aggregation methods to integrate the ethical criteria with asset allocation problems in a LZN environment. The three proposed models are developed for socially responsible investors. The first model (Model 1) is more suitable for general socially responsible investors who aim to obtain the maximum financial goal with the desirable ethical level. The second model (Model 2) is more suitable for general socially responsible investors who wish to achieve both maximum financial and ethical goals simultaneously. Finally, the third model (Model 3) is more proper for risky socially responsible investors who wish to obtain both the maximum financial goal and ethical goals with a confined accuracy level as the portfolio risks. Furthermore, consideration of the predefined number of assets allocated to the portfolio along with the lower and upper bounds of the portion of capital invested in each asset guarantees the diversification of the portfolios.

The proposed approach enjoys several advantages that are highlighted below:

1. The proposed approach is more holistic and flexible than other approaches owing to the presence of LZNs in the evaluation information modeling. The LZNs not only reduce the information loss due to creation of a more flexible, holistic, and accurate structure but also capture the possibilistic and probabilistic constraints simultaneously. These abilities make them suitable for evaluating the information in financial markets;

2. The proposed aggregation methods take into account the interrelationships among all input arguments in a decision-making environment. Although there are some aggregation techniques for fusing the evaluation information when the input arguments are dependent, they are unable to solve decisionmaking problems in a LZN environment. To overcome this shortcoming, our proposed aggregation operators namely LZMM, LZWMM, LZDMM, and LZDWMM operators are more general and more flexible in aggregating the assessment information than the others. The proposed aggregation operators not only consider the interrelationships among all input arguments, but also capture the reliability of information, which can prevent the loss of information in the evaluation information aggregating;

3. The proposed approach functions based on the max-score and score-accuracy trade-off rules and develops three qualitative ethical-financial portfolio models in a LZN environment. Our proposed models are suitable for both the general socially responsible investors and risky socially responsible investors. Moreover, compared to the traditional portfolio models, our proposed models can generate more diversified portfolios according to investors' preferences and examine the trade-off between the financial and ethical goals in addition to that between the score and accuracy values under different circumstances. 


\section{Conclusion}

In order to select the optimal combination of assets in a portfolio based on the trade-off between the financial and ethical criteria when the qualitative evaluation information was incomplete, vague, and uncertain, the current study proposed a comprehensive multi-stage methodology according to the investors' preferences and experts' reliability in a linguistic $Z$ number environment. The main stages of the extended methodology are discussed in the following: (1) The linguistic $Z$-number information was aggregated using MM and DMM operators, and the extended four new aggregation operators were called the Linguistic $Z$-number Muirhead Mean (LZMM), Linguistic $Z$ number Weighted Muirhead Mean (LZWMM), Linguistic $Z$-number Dual Muirhead Mean (LZDMM), and Linguistic $Z$-number Dual Weighted Muirhead Mean (LZDWMM) operators; (2) The score and accuracy values were calculated for the financial and ethical criteria; (3) Three qualitative portfolio optimization models were developed for investors with different preferences. Two qualitative asset allocation models (Models 1 and 2), suitable for the general socially responsible investors, were developed based on the maxscore rule. Finally, the third qualitative portfolio model (Model 3), suitable for the risky socially responsible investors, was designed based on the score-accuracy trade-off rule.

Then, the proposed qualitative models were employed to select portfolios based on a real case. The results indicate that the proposed approach can construct more diversified portfolios based on a trade-off between the financial and ethical criteria based on the investor's preferences. Moreover, the proposed approach could not only consider the interrelationships among all input arguments but also capture the experts' reliability in investment processes.

For future research, linguistic $Z$-numbers can be combined with many aggregation operators such as power aggregation operator, Heronian Mean (HM) operator, etc. Our proposed approach can be developed based on other assumptions, constraints, and objectives such as entropy constraints and transaction cost. Moreover, the proposed approach can be applied to model a multi-period portfolio selection problem.

\section{References}

1. Markowitz, H. "Portfolio selection", J. Finance, 7, pp. 77-91 (1952).

2. Gupta, P., Mehlawat, M.K., and Saxena, A. "Hybrid optimization models of portfolio selection involving financial and ethical considerations", Knowledge-Based Systems, 37, pp. 318-337 (2013).

3. EUROSIF, 2018, European SRI Study, Available at: < http://www.eurosif.org/wp-content/uploads/ 2018/01/Eurosif-SDGs-brochure.pdf >.

4. Ballestero, E., Bravo, M., Perez-Gladish, B., et al. "Socially responsible investment: A multicriteria approach to portfolio selection combining ethical and financial objectives", European Journal of Operational Research, 216, pp. 487-494 (2012).

5. Trenado, M., Romero, M., Cuadrado, M.L., et al. "Corporate social responsibility in portfolio selection: A "goal games" against nature approach", Computers \& Industrial Engineering, 75, pp. 260-265 (2014).

6. An, D., Yang, Y., Chai, X., et al. "Mitigating pollution of hazardous materials from WEEE of China: Portfolio selection for a sustainable future based on multicriteria decision making", Resources Conservation and Recycling, 105, pp. 198-210 (2015).

7. Sehatpour, M.H. and Kazemi, A. "Sustainable fuel portfolio optimization: Integrated fuzzy multiobjective programming and multi-criteria decision making", Journal of Cleaner Production, 176, pp. 304319 (2018).

8. Yang, C.H. "An optimization portfolio decision model of life cycle activity-based costing with carbon footprint constraints for hybrid green power strategies", Computers and Operations Research, 96, pp. 256-271 (2018).

9. Zadeh, L.A. "Fuzzy sets", Information and Control, 8, pp. 338-353 (1965).

10. Turksen, I.B. "Interval valued fuzzy sets based on normal forms", Fuzzy Sets and Systems, 20, pp. 191210 (1986).

11. Dubois, D. and Prade, H., Fundamentals of Fuzzy Sets, Springer, Berlin (2000).

12. Atanassov, K.T. "Intuitionistic fuzzy sets", Fuzzy Sets and Systems, 20, pp. 87-96 (1986).

13. Torra, V. "Hesitant fuzzy sets", International Journal of Intelligent Systems, 25, pp. 529-539 (2010).

14. Chen, N., Xu, Z.S., and Xia, M.M. "Interval-valued hesitant preference relations and their applications to group decision making", Knowledge-Based Systems, 37, pp. 528-540 (2013).

15. Saborido, R., Ruiz, A.B., Bermúdez, J.D., et al. "Evolutionary multi-objective optimization algorithms for fuzzy portfolio selection", Applied Soft Computing, 39, pp. 48-63 (2016).

16. Vercher, E. and Bermúdez, J.D. "Portfolio optimization using a credibility mean-absolute semi-deviation model", Expert Systems with Applications, 42, pp. 7121-7131 (2015). 
17. Zhou, W. and Xu, Z. "Portfolio selection and risk investment under the hesitant fuzzy environment", Knowledge-Based Systems, 144, pp. 21-31 (2018).

18. Zadeh, L.A. "A note on $Z$-numbers", Information Sciences, 181, pp. 2923-2932 (2011).

19. Kang, B., Wei, D., Li, Y., et al. "A method of converting $Z$-number to classical fuzzy number", Journal of Information and Computational Science, 9, pp. 703709 (2012).

20. Azadeh, A. and Kokabi, R. " $Z$-number DEA: A new possibilistic DEA in the context of $Z$-numbers", Advanced Engineering Informatics, 30, pp. 604-617 (2016).

21. Aliev, R.A., Alizadeh, A.V., and Huseynov, O.H. "The arithmetic of discrete $Z$-numbers", Information Sciences, 290, pp. 134-155 (2015).

22. Aliev, R.A., Huseynov, O.H., and Zeinalova, L.M. "The arithmetic of continuous $Z$-numbers", Information Sciences, 373, pp. 441-460 (2016).

23. Bhanu, M.S. and Velammal, G. "Operations on Zadeh's Z-number", IOSR Journal of Mathematics, 11, pp. 88-94 (2015).

24. Bakar, A.S.A. and Gegov, A. "Multi-layer decision methodology for ranking $Z$-numbers", International Journal of Computational Intelligence Systems, 8, pp. 395-406 (2015).

25. Aliev, R.A., Huseynov, O.H., and Serdaroglu, R. "Ranking of $Z$-numbers and its application in decision making", International Journal of Information Technology and Decision Making, 15, pp. 1503-1519 (2016). https://doi.org/10.1142/S0219622016500310

26. Ezadi, S. and Allahviranloo, T. "New multilayer method for $Z$-number ranking using hyperbolic tangent function and convex combination", Intelligent Automation and Soft Computing (2017). https://doi.org/10.1080/10798587.2017.1367146

27. Jiang, W., Xie, C., Luo, Y., et al. "Ranking $Z$-numbers with an improved ranking method for generalized fuzzy numbers", Journal of Intelligent and Fuzzy Systems, 32, pp. 1931-1943 (2017).

28. Qiu, D., Xing, Y., and Dong, R. "On ranking of continuous $Z$-numbers with generalized centroids and optimization problems based on Z-numbers", International Journal of Intelligent System, 33, pp. 4-13 (2018).

29. Yager, R.R. "On Z-valuations using Zadeh's $Z$ numbers", International Journal of Intelligent Systems, 27, pp. 259-278 (2012).

30. Aliev, R.A., Pedrycz, W., and Huseynov, O.H. "Functions defined on a set of $Z$-numbers", Information Sciences, 423, pp. 353-375 (2018).
31. Yang, Y. and Wang, J. "SMAA-based model for decision aiding using regret theory in discrete $Z$-number context", Applied Soft Computing, 65, pp. 590-602 (2018).

32. Shen, K. and Wang, J. " $Z$-VIKOR method based on a new comprehensive weighted distance measure of $Z$ number and its application", IEEE Transactions on Fuzzy Systems, 26(6), pp. 3232-3245 (2018). DOI: 10.1109/TFUZZ.2018.2816581

33. Sadi-Nezhad, S. and Sotoudeh-Anvari, A. "A new data envelopment analysis under uncertain environment with respect to fuzziness and an estimation of reliability", OPSEARCH, 53, pp. 103-115 (2016).

34. Yaakob, A.M. and Gegov, A. "Interactive TOPSIS based group decision making methodology using $Z$ numbers", International Journal of Computational Intelligence Systems, 9, pp. 311-324 (2016).

35. Jirofti, A. and Najafi, A.B. "Portfolio selection using $Z$-number theory: two solution methodologies", International Journal of Fuzzy System, 20(8), pp. 24842496 (2018).

36. Aboutorab, H., Saberi, M., Rajabi Asadabadi, M., et al. "ZBWM: The $Z$-number extension of best worst method and its application for supplier development", Expert Systems with Applications, 107, pp. 115-125 (2018).

37. Peng, H., Wang, X., Wang, T., et al. "Multi-criteria game model based on the pairwise comparisons of strategies with Z-numbers", Applied Soft Computing Journal, 74, pp. 451-465 (2018).

38. Wang, J.Q., Lu, P., and Zhang, H.Y. "Method of multi-criteria group decision-making based on cloud aggregation operators with linguistic information", Information Sciences, 274, pp. 177-91 (2014).

39. Wang, J., Cao, Y., and Zhang, H. "Multi-criteria decision-making method based on distance measure and Choquet integral for linguistic $Z$-numbers", Cognitive Computation, 9, pp. 827-842 (2017).

40. Peng, H. and Wang, J. "Hesitant uncertain linguistic $Z$-numbers and their application in multi-criteria group decision-making problems", International Journal of Fuzzy Systems, 19, pp. 1300-1316 (2017).

41. Liu, P.D. and Teng, F. "Multiple attribute group decision making methods based on some normal neutrosophic number Heronian Mean operators", Journal of Intelligent \& Fuzzy Systems, 32(3), pp. 2375-2391 (2017).

42. Yager, R.R. "Prioritized aggregation operators", International Journal of Approximate Reasoning, 48, pp. 263-274 (2008). 
43. Xu, Y.J. and Wang, H.M. "Approaches based on 2tuple linguistic power aggregation operators for multiple attribute group decision making under linguistic environment", Applied Soft Computing, 11, pp. 39883997 (2011).

44. Zhang, H.M. "Some interval-valued 2-tuple linguistic aggregation operators and application in multi attribute group decision making", Applied Mathematical Modelling, 37, pp. 4269-4282 (2013).

45. Wei, G., Zhao, X., Lin, R., et al. "Uncertain linguistic Bonferroni mean operators and their application to multiple attribute decision making", Applied Mathematical Modelling, 37, pp. 5277-5285 (2013).

46. Wang, J.Q., Wu, J.T., Wang J., et al. "Interval-valued hesitant fuzzy linguistic sets and their applications in multi-criteria decision-making problems", Information Sciences, 288, pp. 55-72 (2014).

47. Wang, X.F., Wang, J.Q., and Yang, W.E. "Multicriteria group decision making method based on intuitionistic linguistic aggregation operators", Journal of Intelligent and Fuzzy Systems, 26, pp. 115-125 (2014).

48. Xu, Z.S. "A method based on linguistic aggregation operators for group decision making with linguistic preference relation", Information Sciences, 166, pp. 19-30 (2004).

49. Zhou, H., Wang, J.Q., Zhang, H.Y., et al. "Linguistic hesitant fuzzy multi-criteria decision-making method based on evidential reasoning", International Journal of Systems Science, 47(2), pp. 314-327 (2016).

50. Liu, P., Chen, S., and Liu, J. "Multiple attribute group decision making based on intuitionistic fuzzy interaction partitioned Bonferroni mean operators", Information Sciences, 411, pp. 98-121 (2017).

51. Liu, P.D. and Jin, F. "The trapezoid fuzzy linguistic Bonferroni mean operators and their application to multiple attribute decision making", Scientia Iranica, 19(6), pp. 1947-1959 (2010).

52. Bonferroni, C. "Sulle medie multiple di potenze", Bolletino Matematica Italiana, 5, pp. 267-270 (1950).

53. Yu, D.J. "Hesitant fuzzy multi-criteria decision making methods based on Heronian mean", Technological and Economic Development of Economy, 23(2), pp. 296315 (2017).

54. Zhu, B., Xu, Z.S., and Xia, M.M. "Hesitant fuzzy geometric Bonferroni means", Information Sciences, 205, pp. 72-85 (2010).

55. Muirhead, R.F. "Some methods applicable to identities and inequalities of symmetric algebraic functions of n letters", Proceedings of the Edinburgh Mathematical Society, 21, pp. 144-162 (1902).
56. Liu, P. and Teng, F. "Some muirhead mean operators for probabilistic linguistic term sets and their applications to multiple attribute decision-making", Applied Soft Computing, 68, pp. 396-431 (2018).

57. Zadeh, L.A. "The concept of a linguistic variable and its application to approximate reasoning-I", Information Sciences, 8, pp. 199-249 (1975).

58. Delgado, M., Verdegay, J.L., and Vila, M.A. "Linguistic decision making models", International Journal of Intelligent Systems, 7, pp. 479-492 (1992).

59. Xu, Z.S. "Uncertain linguistic aggregation operators based approach to multiple attribute group decision making under uncertain linguistic environment", Information Sciences, 168, pp. 171-184 (2004).

60. Xu, Z.S. "A note on linguistic hybrid arithmetic averaging operator in multiple attribute decision-making with linguistic information", Group Decision and $\mathrm{Ne}$ gotiation, 15, pp. 593-604 (2006).

61. Qin, J.D. and Liu, X.W. "2-tuple linguistic Muirhead mean operators for multiple attribute group decision making and its application to supplier selection", Kybernetes, 45(1), pp. 2-29 (2016).

62. Hong, D.H. and Choi, C.H. "Multi-criteria fuzzy decision-making problems based on vague set theory", Fuzzy Sets Systems, 114, pp. 103-113 (2000).

63. Miras-Rodríguez, M.D.M., Carrasco-Gallego, A., and Escobar-Perez, B. "Has the CSR engagement of electrical companies had an effect on their performance? A closer look at the environment", Bus. Strategy Environ., 24(8), pp. 819-835 (2015).

64. Ferrero-Ferrero, I., Fernandez-Izquierdo, M.A., and Munoz-Torres, M.J. "The effect of environmental, social and governance consistency on economic results", Sustainability, 8(10), pp. 1-16 (2016).

65. Escrig-Olmedo, E., Rivera-Lirio, J.M., Munoz-Torres, M.J., et al. "Integrating multiple ESG investors' preferences into sustainable investment: A fuzzy multicriteria methodological approach", Journal of Cleaner Production, 162, pp. 1334-1345 (2017).

66. Phillis, Y.A. and Andriantiatsaholiniaina, L.A. "Sustainability: an ill-defined concept and its assessment using fuzzy logic", Ecol. Econ., 37(3), pp. 435-456 (2001).

67. Spernza, M.G. "A heuristic algorithm for a portfolio optimization model applied to the Milan Stock Market", Computers and Operations Research, 23, pp. 433-441 (1996).

68. Mansini, R. and Speranza, M.G. "Heuristic algorithms for the portfolio selection problem with minimum transaction lots", European Journal of Operational Research, 114, pp. 219-233 (1999).

\section{Appendix A}

Theorem 1. Let $z_{i}=\left(A_{\phi(i)}, B_{\varphi(i)}\right)(i=1, \ldots, k)$ be a set of LZNs and $P=\left(P_{1}, P_{2}, \ldots, P_{k}\right) \in R^{k}$ be 


$$
\begin{aligned}
L Z M M^{p}\left(Z_{1}, Z_{2}, \cdots, Z_{k}\right)= & f^{*^{-1}}\left(\left(\frac{1}{k !}\left(\sum_{\theta \in S_{k}}\left(\prod_{i=1}^{k}\left(f^{*}\left(A_{\phi(\theta(i)}\right)\right)^{p_{i}}\right)\right)\right)^{\frac{1}{\sum_{i=1}^{k} p_{i}}}\right) \\
& g^{*^{-1}}\left(\left(\frac{\sum_{\theta \in S_{k}}\left(\prod_{i=1}^{k}\left(f^{*}\left(A_{\phi(\theta(i))}\right)\right)^{p_{i}} \times \prod_{i=1}^{k}\left(g^{*}\left(B_{\varphi(\theta(i))}\right)\right)^{p_{i}}\right)}{\sum_{\theta \in S_{k}}\left(\prod_{i=1}^{k}\left(f^{*}\left(A_{\phi(\theta(i))}\right)\right)^{p_{i}}\right)}\right)\right)
\end{aligned}
$$

Box A.I

a parametric vector. Then, the aggregated result acquired based on LZMM operator is an LZN and it is indicated by Eq. (A.1) as shown in Box A.I.

Proof. According to Definition 4, it is clear that the aggregated value is an LZN. Now, by applying the mathematical induction method, Eq. (A.1) is easily proven in the following.

Firstly, it is assumed that $k=2$. Hence, if $k=2$, then $S_{2}=\{(\theta(1), \theta(2)),(\theta(2), \theta(1))\}$. According to Definition 4 , we have:

$$
\begin{aligned}
& \left(Z_{\theta(1)}\right)^{P_{1}}=\left(f^{*^{-1}}\left(\left(f^{*}\left(A_{\phi(\theta(1))}\right)\right)^{P_{1}}\right),\right. \\
& \left.g^{*^{-1}}\left(\left(g^{*}\left(B_{\varphi(\theta(1))}\right)\right)^{P_{1}}\right)\right), \\
& \left(Z_{\theta(1)}\right)^{P_{2}}=\left(f^{*^{-1}}\left(\left(f^{*}\left(A_{\phi(\theta(1))}\right)\right)^{P_{2}}\right),\right. \\
& \left.g^{*^{-1}}\left(\left(g^{*}\left(B_{\varphi(\theta(1))}\right)\right)^{P_{2}}\right)\right), \\
& \left(Z_{\theta(2)}\right)^{P_{1}}=\left(f^{*^{-1}}\left(\left(f^{*}\left(A_{\phi(\theta(2))}\right)\right)^{P_{1}}\right),\right. \\
& \left.g^{*^{-1}}\left(\left(g^{*}\left(B_{\varphi(\theta(2))}\right)\right)^{P_{1}}\right)\right), \\
& \left(Z_{\theta(2)}\right)^{P_{2}}=\left(f^{*^{-1}}\left(\left(f^{*}\left(A_{\phi(\theta(2))}\right)\right)^{P_{2}}\right),\right. \\
& \left.g^{*^{-1}}\left(\left(g^{*}\left(B_{\varphi(\theta(2))}\right)\right)^{P_{2}}\right)\right), \\
& \left(Z_{\theta(1)}\right)^{P_{1}} \times\left(Z_{\theta(2)}\right)^{P_{2}}=\left(f ^ { * ^ { - 1 } } \left(\left(f^{*}\left(A_{\phi(\theta(1))}\right)\right)^{P_{1}}\right.\right.
\end{aligned}
$$

$$
\begin{aligned}
& \left.\times\left(f^{*}\left(A_{\phi(\theta(2))}\right)\right)^{P_{2}}\right), \\
& g^{*^{-1}}\left(\left(g^{*}\left(B_{\varphi(\theta(1))}\right)\right)^{P_{1}}\right. \\
& \left.\left.\times\left(g^{*}\left(B_{\varphi(\theta(2))}\right)\right)^{P_{2}}\right)\right),
\end{aligned}
$$

$$
\begin{aligned}
\left(Z_{\theta(2)}\right)^{P_{1}} & \times\left(Z_{\theta(1)}\right)^{P_{2}}=\left(f ^ { * ^ { - 1 } } \left(\left(f^{*}\left(A_{\phi(\theta(2))}\right)\right)^{P_{1}}\right.\right. \\
& \left.\times\left(f^{*}\left(A_{\phi(\theta(1))}\right)\right)^{P_{2}}\right) \\
& g^{*^{-1}}\left(\left(g^{*}\left(B_{\varphi(\theta(2))}\right)\right)^{P_{1}}\right. \\
& \left.\left.\times\left(g^{*}\left(B_{\varphi(\theta(1))}\right)\right)^{P_{2}}\right)\right)
\end{aligned}
$$

The rest of equations are shown in Box A.II.

Obviously, Theorem 1 is true for $k=2$. Now, it is assumed that this theorem be true for $k=t$; therefore, we will have the equation shown in Box A.III. Consequently, for $k=t+1$, we can obtain the expression shown in Box A.IV. Since this theorem is true for $k=t$, it will be also true for $k=t+1$. Finally, according to the mathematical induction, Eq. (A.1) is true for all $k$.

\section{Appendix B}

Theorem 5. Let $z_{i}=\left(A_{\phi(i)}, B_{\varphi(i)}\right)(i=1, \ldots, k)$ be a set of LZNs and $P=\left(P_{1}, P_{2}, \ldots, P_{k}\right) \in R^{k}$ be a parametric vector. Then, the aggregated result acquired based on LZDMM operator is an LZN presented by Eq. (B.1) shown in Box B.I.

Proof. According to Definition 4, it is obvious that the aggregated value obtained by LZDMM operator is 


$$
\begin{aligned}
& \left(\left(Z_{\theta(1)}\right)^{P_{1}} \times\left(Z_{\theta(2)}\right)^{P_{2}}\right)+\left(\left(Z_{\theta(2)}\right)^{P_{1}} \times\left(Z_{\theta(1)}\right)^{P_{2}}\right) \\
& =\left(\begin{array}{c}
f^{*^{-1}}\left(\left(\left(f^{*}\left(A_{\phi(\theta(1))}\right)\right)^{P_{1}} \times\left(f^{*}\left(A_{\phi(\theta(2))}\right)\right)^{P_{2}}\right)+\left(\left(f^{*}\left(A_{\phi(\theta(2))}\right)\right)^{P_{1}} \times\left(f^{*}\left(A_{\phi(\theta(1))}\right)\right)^{P_{2}}\right)\right) \\
g^{*^{-1}}\left(\begin{array}{c}
\left(\left(\left(f^{*}\left(A_{\phi(\theta(1))}\right)\right)^{P_{1}} \times\left(f^{*}\left(A_{\phi(\theta(2 t))}\right)\right)^{P_{2}}\right) \times\left(\left(g^{*}\left(B_{\varphi(\theta(1))}\right)\right)^{P_{1}} \times\left(g^{*}\left(B_{\varphi(\theta(2))}\right)\right)^{P_{2}}\right)\right) \\
\left.\frac{+\left(\left(\left(f^{*}\left(A_{\phi(\theta(2))}\right)\right)^{P_{1}} \times\left(f^{*}\left(A_{\phi(\theta(1))}\right)\right)^{P_{2}}\right) \times\left(\left(g^{*}\left(B_{\varphi(\theta(2))}\right)\right)^{P_{1}} \times\left(g^{*}\left(B_{\varphi(\theta(1))}\right)\right)^{P_{2}}\right)\right.}{\left(\left(f^{*}\left(A_{\phi(\theta(1))}\right)\right)^{P_{1}} \times\left(f^{*}\left(A_{\phi(\theta(2))}\right)\right)^{P_{2}}\right)+\left(\left(f^{*}\left(A_{\phi(\theta(2))}\right)\right)^{P_{1}} \times\left(f^{*}\left(A_{\phi(\theta(1))}\right)\right)^{P_{2}}\right)}\right)
\end{array}\right)
\end{array}\right) \\
& \frac{1}{2}\left(\left(Z_{\theta(1)}\right)^{P_{1}} \times\left(Z_{\theta(2)}\right)^{P_{2}}\right)+\left(\left(Z_{\theta(2)}\right)^{P_{1}} \times\left(Z_{\theta(1)}\right)^{P_{2}}\right)= \\
& \left(\begin{array}{c}
f^{*^{-1}}\left(\begin{array}{c}
\left.\frac{1}{2}\left(\left(f^{*}\left(A_{\phi(\theta(1))}\right)\right)^{P_{1}} \times\left(f^{*}\left(A_{\phi(\theta(2))}\right)\right)^{P_{2}}\right)+\left(\left(f^{*}\left(A_{\phi(\theta(2))}\right)\right)^{P_{1}} \times\left(f^{*}\left(A_{\phi(\theta(1))}\right)\right)^{P_{2}}\right)\right) \\
g^{*^{-1}}\left(\begin{array}{c}
\left(\left(\left(f^{*}\left(A_{\phi(\theta(1))}\right)\right)^{P_{1}} \times\left(f^{*}\left(A_{\phi(\theta(2))}\right)\right)^{P_{2}}\right) \times\left(\left(g^{*}\left(B_{\varphi(\theta(1))}\right)\right)^{P_{1}} \times\left(g^{*}\left(B_{\varphi(\theta(2))}\right)\right)^{P_{2}}\right)\right) \\
\frac{+\left(\left(\left(f^{*}\left(A_{\phi(\theta(2))}\right)\right)^{P_{1}} \times\left(f^{*}\left(A_{\phi(\theta(1))}\right)\right)^{P_{2}}\right) \times\left(\left(g^{*}\left(B_{\varphi(\theta(2))}\right)\right)^{P_{1}} \times\left(g^{*}\left(B_{\varphi(\theta(1))}\right)\right)^{P_{2}}\right)\right)}{\left(\left(f^{*}\left(A_{\phi(\theta(1))}\right)\right)^{P_{1}} \times\left(f^{*}\left(A_{\phi(\theta(2))}\right)\right)^{P_{2}}\right)+\left(\left(f^{*}\left(A_{\phi(\theta(2))}\right)\right)^{P_{1}} \times\left(f^{*}\left(A_{\phi(\theta(1))}\right)\right)^{P_{2}}\right)}
\end{array}\right)
\end{array}\right)
\end{array}\right. \\
& \operatorname{LZMM}^{p}\left(Z_{1}, Z_{2}\right)=\left(\frac{1}{2}\left(\left(Z_{\theta(1)}\right)^{P_{1}} \times\left(Z_{\theta(2)}\right)^{P_{2}}\right)+\left(\left(Z_{\theta(2)}\right)^{P_{1}} \times\left(Z_{\theta(1)}\right)^{P_{2}}\right)\right)^{\frac{1}{p_{1}+p_{2}}}=
\end{aligned}
$$

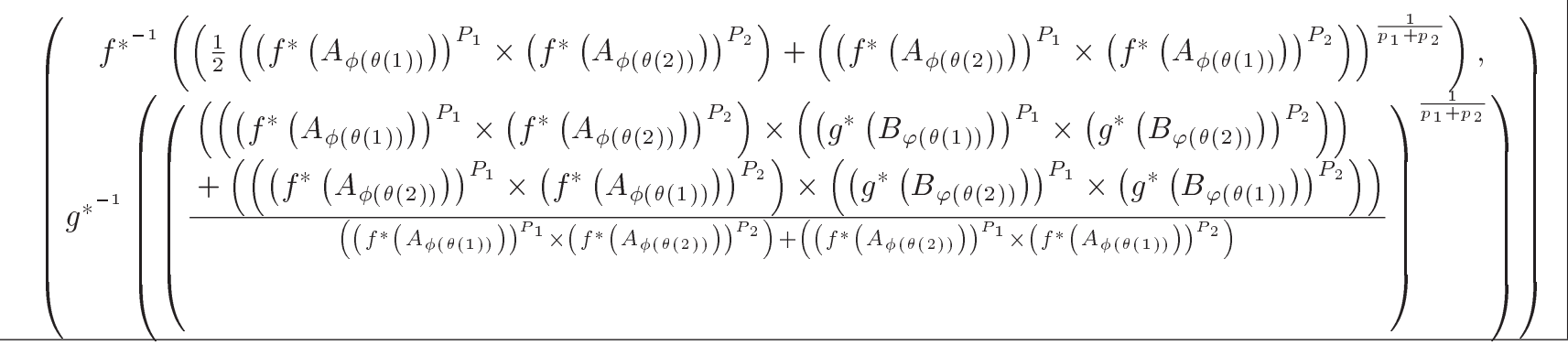

Box A.II

$\operatorname{LZMM}^{p}\left(Z_{1}, Z_{2}, \ldots, Z_{t}\right)=\left(\begin{array}{c}f^{*^{-1}}\left(\left(\frac{1}{t !}\left(\sum_{\theta \in S_{t}}\left(\prod_{i=1}^{t}\left(f^{*}\left(A_{\phi(\theta(i))}\right)\right)^{p_{i}}\right)\right)\right)^{\frac{1}{\sum_{i=1}^{t} p_{i}}}\right), \\ g^{*^{-1}}\left(\left(\frac{\sum_{\theta \in S_{t}}\left(\prod_{i=1}^{t}\left(f^{*}\left(A_{\phi(\theta(i))}\right)\right)^{p_{i}} \times \prod_{i=1}^{t}\left(g^{*}\left(B_{\varphi(\theta(i))}\right)\right)^{p_{i}}\right)}{\sum_{\theta \in S_{t}}\left(\prod_{i=1}^{t}\left(f^{*}\left(A_{\phi(\theta(i))}\right)\right)^{p_{i}}\right)}\right)^{\frac{1}{\sum_{i=1}^{t} p_{i}}}\right)\end{array}\right)$

Box A.III

$$
L Z M M^{p}\left(Z_{1}, Z_{2}, \ldots, Z_{t}, Z_{t+1}\right)=\left(\begin{array}{c}
f^{*^{-1}}\left(\left(\frac{1}{(t+1) !}\left(\sum_{\theta \in S_{t+1}}\left(\prod_{i=1}^{t+1}\left(f^{*}\left(A_{\phi(\theta(i))}\right)\right)^{p_{i}}\right)\right)\right)^{\frac{1}{t+\sum_{i=1}} p_{i}}\right) \\
g^{*^{-1}}\left(\left(\frac{\sum_{\theta \in S_{t+1}}\left(\prod_{i=1}^{t+1}\left(f^{*}\left(A_{\phi(\theta(i))}\right)\right)^{p_{i}} \times \prod_{i=1}^{t+1}\left(g^{*}\left(B_{\varphi(\theta(i))}\right)\right)^{p_{i}}\right)}{\sum_{\theta \in S_{t+1}}\left(\prod_{i=1}^{t+1}\left(f^{*}\left(A_{\phi(\theta(i))}\right)\right)^{p_{i}}\right)}\right)\right.
\end{array}\right)
$$


$\left.\operatorname{LZDMM} M^{p}\left(Z_{1}, Z_{2}, \ldots, Z_{k}\right)=\left(\begin{array}{l}f^{*^{-1}}\left(\frac{1}{\sum_{i=1}^{k} p_{i}}\left(\left(\prod_{\theta \in S_{k}}\left(\sum_{i=1}^{k} p_{i} f^{*}\left(A_{\phi(\theta(i))}\right)\right)\right)\right.\right. \\ g^{*^{-1}}\left(\left(\prod_{\theta \in S_{k}}\left(\frac{\sum_{i=1}^{k}\left(p_{i} f^{*}\left(A_{\phi(\theta(i))}\right) \times g^{*}\left(B_{\varphi(\theta(i))}\right)\right)}{\sum_{i=1}^{k}\left(p_{i} f^{*}\left(A_{\phi(\theta(i))}\right)\right)}\right)\right)\right.\end{array}\right)\right)$

Box B.I

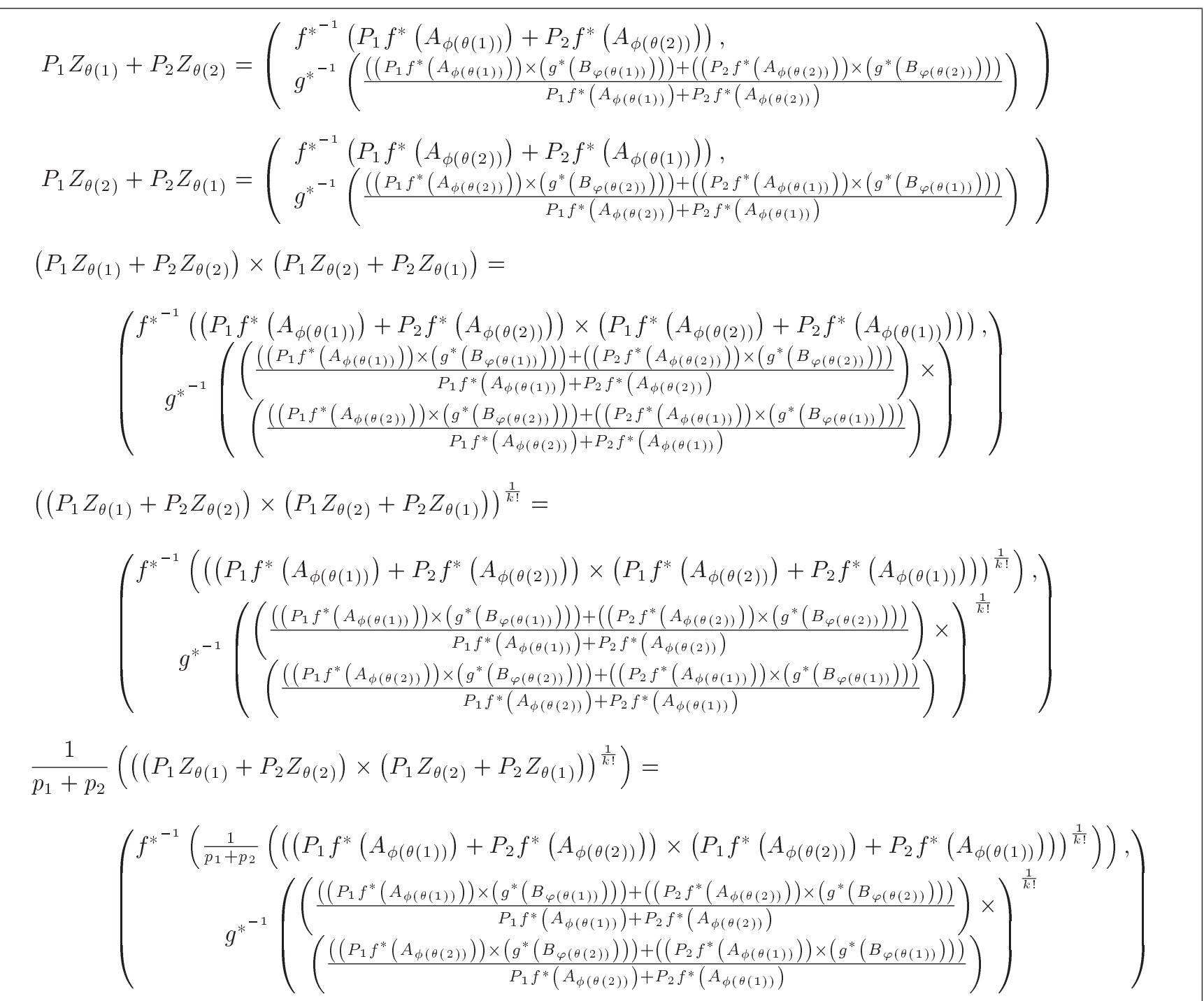

Box B.II

an LZN. Now, by applying the mathematical induction method, Eq. (B.1) is easily proven in the following.

Firstly, it is assumed $k=2$. Hence, if $k=2$, then $S_{2}=\{(\theta(1), \theta(2)),(\theta(2), \theta(1))\}$. According to Definition 4 , we have:

$$
P_{1} Z_{\theta(1)}=\left(f^{*^{-1}}\left(P_{1} f^{*}\left(A_{\phi(\theta(1))}\right)\right), B_{\varphi(\theta(1))}\right)
$$

$$
\begin{aligned}
& P_{2} Z_{\theta(1)}=\left(f^{*^{-1}}\left(P_{2} f^{*}\left(A_{\phi(\theta(1))}\right)\right), B_{\varphi(\theta(1))}\right), \\
& P_{1} Z_{\theta(2)}=\left(f^{*^{-1}}\left(P_{1} f^{*}\left(A_{\phi(\theta(2))}\right)\right), B_{\varphi(\theta(2))}\right) \\
& P_{2} Z_{\theta(2)}=\left(f^{*^{-1}}\left(P_{2} f^{*}\left(A_{\phi(\theta(2))}\right)\right), B_{\varphi(\theta(2))}\right) .
\end{aligned}
$$

The rest of equations are shown in Box B.II.

Obviously, Theorem 5 is true for $k=2$. Now, 


$$
\begin{aligned}
\operatorname{LZDM} M^{p}\left(Z_{1}, Z_{2}, \ldots, Z_{t}\right)= & \left(f ^ { * ^ { - 1 } } \left(\frac{1}{\sum_{i=1}^{t} p_{i}}\left(\left(\prod_{\theta \in S_{t}}\left(\sum_{i=1}^{t} p_{i} f^{*}\left(A_{\phi(\theta(i))}\right)\right)\right)\right)\right.\right. \\
& g^{*^{-1}}\left(\left(\prod_{\theta \in S_{t}}\left(\frac{\sum_{i=1}^{t}\left(p_{i} f^{*}\left(A_{\phi(\theta(i))}\right) \times g^{*}\left(B_{\varphi(\theta(i))}\right)\right)}{\sum_{i=1}^{t}\left(p_{i} f^{*}\left(A_{\phi(\theta(i))}\right)\right)}\right)\right)\right.
\end{aligned}
$$

$$
\begin{aligned}
\operatorname{LZDMM} M^{p}\left(Z_{1}, Z_{2}, \ldots, Z_{t}, Z_{t+1}\right)= & \left(f^{*^{-1}}\left(\frac{1}{\sum_{i=1}^{t+1} p_{i}}\left(\left(\prod_{\theta \in S_{t+1}}\left(\sum_{i=1}^{t+1} p_{i} f^{*}\left(A_{\phi(\theta(i))}\right)\right)\right)^{\frac{1}{(t+1) !}}\right)\right),\right. \\
& g^{*^{-1}}\left(\left(\prod_{\theta \in S_{t+1}}\left(\frac{\sum_{i=1}^{t+1}\left(p_{i} f^{*}\left(A_{\phi(\theta(i))}\right) \times g^{*}\left(B_{\varphi(\theta(i))}\right)\right)}{\sum_{i=1}^{t+1}\left(p_{i} f^{*}\left(A_{\phi(\theta(i))}\right)\right)}\right)\right)\right.
\end{aligned}
$$

Box B.IV

it is assumed that this theorem be true for $k=t$; therefore, we will have the equation shown in Box B.III. Consequently, for $\mathrm{k}=\mathrm{k}+1$, we can obtain the expression shown in Box B.IV. Since this theorem holds for $k=t$, it will also hold for $k=t+1$. Finally, according to the mathematical induction, Eq. (B.1) is true for all $k$ 's.

\section{Biographies}

Amir Hosein Mahmoodi received his BSc degree from Islamic Azad University of Hamedan, Iran 2007 and MSc degree in Industrial Engineering from Islamic Azad University of Qazvin, Iran 2012. Now, he is studying at the Department of Industrial Engineering, Science and Research branch, Islamic Azad University, Tehran, Iran. His research interests include mathematical modeling, optimization methods, portfolio selection, decision theory with uncertain information, fuzzy theory, and $Z$-numbers.

Seyed Jafar Sadjadi received his PhD from University of Waterloo, Canada. His research interests mainly focuses on solving different classes of optimization problems in industrial engineering areas such as supply chain management, portfolio optimization, optimal pricing, etc. He has been working at Iran University of
Science and Technology since 2001.

Soheil Sadi-Nezhad received his $\mathrm{PhD}$ in Industrial Engineering. His recent researches focus on the real time optimization and data analysis collected from the Inertial Measurement Units (IMU). Most of his researches focus on optimization under uncertainty, imprecision, and partial truth, especially when it comes to learning process. In his studies, he employed different new approaches such as Artificial Intelligence, Neural Network, Type 1 and 2 Fuzzy sets, $Z$-numbers, Clustering Analysis, stochastic dynamic programming, Machine Learning (SVM), and other soft computing techniques to develop new products or services.

Roya Soltani is currently an Assistant Professor at the Department of Industrial Engineering, Khatam University, Tehran, Iran. Her research interests include Data Envelopment Analysis (DEA), decision theory, fuzzy theory, evolutionary algorithms, and reliability.

Farzad Movahedi Sobhani is currently an Assistant Professor at the Department of Industrial Engineering, Science and Research branch, Islamic Azad University, Tehran, Iran. His main research interests include MCDM, supply chain management, business dynamics, and multivariate-analysis. 